\title{
Th2-cytokines impair innate immune responses to rhinovirus in respiratory epithelial cells
}

\begin{tabular}{|c|c|}
\hline Journal: & Allergy \\
\hline Manuscript ID: & ALL-2014-00633.R1 \\
\hline Wiley - Manuscript type: & Original Article: Experimental Allergy and Immunology \\
\hline Date Submitted by the Author: & $\mathrm{n} / \mathrm{a}$ \\
\hline Complete List of Authors: & $\begin{array}{l}\text { Contoli, Marco; University of Ferrara, Research Centre on Asthma and } \\
\text { COPD } \\
\text { Ito, Kazuhiro; Imperial College, Airway Disease, National Heath and Lung } \\
\text { Institute } \\
\text { Padovani, Anna; University of Ferrara, Research centre on Asthma and } \\
\text { COPD } \\
\text { Poletti, Donatella; University of Ferrara, ENT Unit, Department of } \\
\text { Biomedical and Surgical Sciences } \\
\text { Marku, Brunilda; University of Ferrara, Research centre on Asthma and } \\
\text { COPD } \\
\text { Edwards, Michael; Imperial College London, Department of Respiratory } \\
\text { Medicine London } \\
\text { Stanciu, Luminita; Imperial College London, Department of Respiratory } \\
\text { Medicine } \\
\text { Gnesini, Giulia; University of Ferrara, Research centre on Asthma and } \\
\text { COPD } \\
\text { Pastore, Antonio; University of Ferrara, ENT Unit, Department of } \\
\text { Biomedical and Surgical Sciences } \\
\text { Spanevello, Antonio; University of Insubria and Fondazione Maugeri, } \\
\text { Respiratory Diseases } \\
\text { Morelli, Paolo; Cros NT, Center of Excellence for Clinical Trial Data } \\
\text { Johnston, Sebastian; Imperial College London, Department of Respiratory } \\
\text { Medicine } \\
\text { Caramori, Gaetano; University of Ferrara, Research centre on Asthma and } \\
\text { COPD } \\
\text { Papi, Alberto; University of Ferrara, Research centre on Asthma and COPD }\end{array}$ \\
\hline Keywords : & asthma, innate immunity, virus, basic mechanisms \\
\hline
\end{tabular}


1 Th2-cytokines impair innate immune responses to rhinovirus in respiratory epithelial cells 2

3 Marco Contoli ${ }^{1}$, Kazuhiro Ito $^{2}$, Anna Padovani $^{1}$, Donatella Poletti ${ }^{3},{ }^{4}$, Brunilda Marku ${ }^{1}$, Michael R.

$4 \quad$ Edwards $^{4}$, Luminita A. Stanciu ${ }^{4}$, Giulia Gnesini ${ }^{1}$, Antonio Pastore ${ }^{3}$, Antonio Spanevello ${ }^{5}, \underline{\text { Paolo }}$

$5 \quad$ Morelli $^{6}$, Sebastian L. Johnston ${ }^{4}$, Gaetano Caramori ${ }^{1}$, Alberto Papi ${ }^{1}$.

6

$7{ }^{1}$ Research Centre on Asthma and COPD, Department of Medical Sciences, University of Ferrara, 8 Italy

$9 \quad{ }^{2}$ Airway Disease, National Heath and Lung Institute, Imperial College, London, UK.

$10{ }^{3}$ ENT Unit, Department of Biomedical and Surgical Sciences, University of Ferrara, Italy

$11{ }^{4}$ Airway Disease Infection Section, National Heart and Lung Institute, Imperial College and MRC

12 and Asthma UK Centre in Allergic Mechanisms of Asthma, London, UK

$13{ }^{5}$ University of Insubria, Varese; Fondazione Maugeri, IRCCS, Tradate

$14 \mid \frac{{ }^{6} \text { Cros NT, Verona, Italy. }}{}$

15

16 Address correspondence to:

17 Marco Contoli, MD, PhD

18 Research Centre on Asthma and COPD, Department of Medical Sciences, University of Ferrara, 19 Italy

20 Via Savonarola 9, 44121 Ferrara, Italy

21 Tel: +390532236908

22 Fax: +390532210297

23 Email: ctm@unife.it 
$1 \quad$ Word count (text): 2554

2 Key words: asthma, innate immunity, virus, Th2 inflammation, interferon.

3

4

10

11

12

13

14

15

16

17

18

19

20

21

22

23

24

25

26

27

28

29

30

31

32

33

34

35

36

37

38

39

40

41

42

43

44

45

46

47

48

49

50

51

52

53

54

55

56

57

58

59

60 
1 Abstract (word count: $246 \underline{245}$ )

2 Background: Asthma and other Th2 inflammatory conditions have been associated with increased 3 susceptibility to viral infections. The mechanisms by which Th2 cytokines can influence immune 4 responses to infections are largely unknown.

5 Methods: We measured the effects of Th2 cytokines (IL-4 and IL-13) on bronchial epithelial cell

6 innate immune antiviral responses by assessing interferon (IFN- $\beta$ and IFN- $\lambda 1$ ) induction following

7 rhinovirus (RV)-16 infection. We also investigated the modulatory effects of Th2 cytokines on

8 signalling pathways involved in the rhinovirus induced interferon production and inflammatory

9 easeade including-Toll-like receptor (TLR)-3, interferon-responsive factor (IRF)-3, and nuclear factor (NF)-kB-, i.e. key molecules and transcription factors involved in the rhinovirus-induced interferon production and inflammatory cascade. Pharmacological and redox modulation by the reducing agent $\mathrm{N}$-acetyleysteine onof these pathways was also testedassessed.

13 Results: Th2 cytokines impaired RV16-induced interferon production, increased rhinovirus

14 replication and impaired TLR3 expression in bronchial epithelial cells. These results were

15 replicated in vivo: we found increased IL-4 mRNA levels in nasal epithelial cells from nasal

16 brushing of atopic rhinitis patients and a parallel reduction of TLR3 expression and increased RV16

17 replication compared to non-atopic subjects. Mechanistically, Th2 cytokines impaired RV-16

18 induced activation of IRF3, but had no effects on RV16-induced NF-kB activation in bronchial

19 epithelial cell cultures. N-acetylcysteine and phosphoinositide 3-kinase (PI3k) inhibitor restored the

20 inhibitory effects of Th2 cytokines over RV-16 induced activation of IRF3 and production of IFNs.

21 Conclusions: IL-4 and IL-13, through inhibition of TLR3 expression and exidant mediated

22 imhibition of signalling (IRF-3,), impair immune response to RV-16 infection. These data suggest

23 that $\mathrm{Th} 2$ conditions increase susceptibility to infections and identify a-pharmacological

24 approachapproaches with potential to restore impaired immune response in these conditions. 
2 Introduction

3 Asthma is a chronic disorder of the airways that is typically inflammatory in nature and

$4 \quad$ affects millions of children and adults (1).(1).

$5 \quad$ Viral infections of the respiratory tract early in life are associated with an increased risk of

6 developing asthma later in life and are also the most frequent causes of asthma exacerbations in

7 both children and adults (2). Rhinoviruses are the respiratory virus type that is most frequently

8 detected during asthma exacerbations (3). The innate immune response is at the forefront of the

9 defence against respiratory infections. Impaired innate immune responses have been reported to be

10 a possible mechanism of increased susceptibility to infections among asthmatic patients $(2,4,5)$. $(2)$.

11 Rhinoviruses are the respiratory virus type that is most frequently detected during asthma

12 exacerbations (3). The innate immune response is at the forefront of the defence against respiratory

13 infections.

14 Impaired innate immune responses have been reported to be a possible mechanism of

$15 \underline{\text { increased susceptibility to infections among asthmatic patients }(2,4,5) \text {. The molecular mechanisms }}$

16 underlying such a deficiency are still largely unknown.

17 The cytokines produced by the Th2 subset of lymphocytes, such as IL-4 and IL-13, have

18 been proven to be important drivers of allergic airway inflammation in asthma, although a) the

19 mechanisms underlying their roles in the complex pathogenesis are still widely debated andb) not

20 all asthmatic patients have higha preponderant $\mathrm{Th} 2$ oriented inflammatory profile in the airways (6).

21 We recently documented that in vivo Th2 inflammation is associated with impaired ex vivo

22 immune responses to rhinovirus infection in bronchial epithelial cells from asthmatic children and

23 also in cells from atopic children without any established clinical manifestations of asthma (7).

24 These data accord with previous in vitro (8-10) and in vivo data (11) and suggest that the Thz

25 inflammation influences the integrity of the innate immune responses and the outcomes of

26 infections. 
Oxidative stress has previously been found to influence the molecular pathways that are commonly involved in rhinovirus-induced intracellular signalling and proinflammatory activities $(12,13)$. Furthermore, it has been shown that oxidative stress can impair innate immune responses by interfering with the intracellular interferon signalling $(14,15)$. Thus, modulation of the intracellular redox state represents a potential pharmacological target for interfering with the intimate mechanisms that are related to viral infection and the immunological and inflammatory substrates and consequences of such infections.

(6) nor allergen driven clinical manifestations. We recently documented that in vivo Th2 inflammation is associated with impaired ex vivo immune responses to rhinovirus infection in

10 bronchial epithelial cells from asthmatic children and also in cells from atopic children without any

11 established clinical manifestations of asthma (7). These data accord with previous in vitro (8-10)

12 and in vivo data (11) suggest that the Th2 inflammation influences the integrity of the innate

13 immune responses and the outcomes of infections. Thus, intercepting the mechanisms of Th2

14 interference upon innate immune response may improve the ability of counteract the susceptibility

15 to infections in these clinical conditions.

16 Oxidative stress has previously been found to influence the molecular pathways that are

17 commonly involved in rhinovirus-induced intracellular signalling and proinflammatory activities

18 (12,13). Furthermore, it has been shown that oxidative stress can impair innate immune responses

19 by interfering with the intracellular interferon signalling $(14,15)$. In addition, phosphoinositide 3-

20 kinases (PI3K) is a large family of intracellular signalling kinases involved in the both innate

21 immune response to infections and Th2 inflammation (16-20). Thus, modulation of the intracellular

22 redox state and of PI3k immunoregulatory activities represent potential pharmacological targets of

23 interference with the substrates of immunological and inflammatory responses to viral infections.

Here, we evaluated the effects of Th2 cytokines (IL-4 and IL-13) on innate immune

25 responses as assessed by type I (IFN- $\beta$ ) and type III (IFN- $\lambda 1)$ interferon production against

26 rhinovirus infection in bronchial epithelial cells. We also identifiedevaluated the signalling 
1

2

3

4

5

6

7

8

9

10

11

12

13

14

15

16

17

18

19

20

21

22

23

24

25

26

27

28

29

30

31

32

33

34

35

36

37

38

39

40

41

42

43

44

45

46

47

48

49

50

51

52

53

54

55

56

57

58

59

60
1 pathways involved in the inhibitory effects of Th2 cytokines over key molecules (TLR-3) and

2 transcription factors (IRF3 and NF-kB) involved in the innate immune responses to virat

3 infectionsrhinovirus and tested potential methods of pharmacological modulation.

5 


\section{Methods}

\section{Cell cultures and in vitro rhinovirus infections}

3 The immortalized human bronchial epithelial cell line BEAS-2B was obtained from the

American Type Culture Collection (Rockville, Md, USA) and cultured as previously described (16).

Primary human bronchial epithelial cells (HBECs) were obtained from bronchial brushings of non-

atopic, non-asthmatic and non-smoking subjects (who underwent bronchoscopy for clinical reasons

Supplementary Table 1) and cultured as previously described (7,16,17).

Primary epithelial cells of the nasal mucosae of five atopic rhinitis and six non-atopic healthy non-smoker volunteers were harvested by nasal scraping and freshly cultured in BEG medium.The immortalized human bronchial epithelial cell line BEAS-2B was obtained from the American Type Culture Collection (Rockville, Md, USA) and cultured as previously described (21). Primary human bronchial epithelial cells (HBECs) were obtained from bronchial brushings of nonatopic, non-asthmatic and non-smoking subjects (who underwent bronchoscopy for clinical reasons - Supplementary Table 1) and cultured as previously described $(7,21,22)$.

$\underline{\text { Primary epithelial cells of the nasal mucosae of five atopic rhinitis and six non-atopic }}$ healthy non-smoker volunteers were harvested by nasal scraping and freshly cultured in BEG medium (Supplementary Table 2). When confluent, total RNA was extract according to manufacturer's instructions (Qiagen). Atopic status was defined as the presence of at least one positive response to skin pricks tests for common local aeroallergens (the

The demographic characteristics are reportedof the patients enrolled in the online supporting information).

Thestudy and the experimental conditions of the cell cultures and stimulationstimulations are detailed in the online supporting information and in Supplementary Table 1 and 2.

The study was approved by the local ethics committee of the University Hospital of Ferrara, and informed consent was obtained from each participant in accordance with the principles outlined in the Declaration of Helsinki. 
2 Viral stocks

3 Rhinovirus type 16 (RV16) was obtained from the Health Protection Agency Culture

4 Collections, Salisbury, United Kingdom and used for all of the experimental conditions described.

5 The virus was used at a multiplicity of infection (MOI) of 5 in all experiments (1823). 6

\section{Quantitative TaqMan real-time RT-PCR}

\section{Interferon and CXCL8 protein assays}

24 and CXCL8 levels in cell-culture supernatants were performed according to the manufacturers'

25 instructions. The sensitivities, specificities, and sources for the individual ELISAs have been

26 previously detailed (7) $\underline{(7)}$. 
2 Measurement of transcription factor activation

3 Nuclear extracts were prepared from the BEAS2B cells using a nuclear protein extraction kit 4 (Active Motif, Rixensart, Belgium). Activated NFkB, IRF3 and STAT1 in 10- $\mu$ g nuclear extracts

5 were detected by evaluating their bindings to oligonucleotides targeting each binding site using 6 ELISA-based assays (TransAM Transcription Factor Assay kits for NFkB, IRF3 and the STAT 7 family; Active Motif, La Hulpe, Belgium) following the manufacturer's recommendations.

\section{$9 \quad$ Statistical analyses}

10 The data are expressed as the means and the standard errors of the means of at least 4 experiments. Differences between the conditions at each time point were calculated with unpaired $t$ tests. Multiple comparisons were first analysed with ANOVAs. When significant $(p<0.05)$ differences between groups/conditions were found, post hoc analyses were performed with paired or unpaired $t$ tests as appropriate. Values below .05 were considered significant. In cases of multiple comparisons, the reported $p$ values refer to analyses that were adjusted with the Bonferroni eorrection.Comparisons between conditions were performed by means of paired or unpaired non parametric tests (Wilcoxon test or Mann-Whitney test respectively). After the evaluation of the effects of rhinovirus infection (e.g. on interferon induction and/or transcription factors activation), $\underline{\text { in case of multiple tests, paired comparisons were performed using a Hierarchical method to control }}$ for multiplicity based on concentration, timing or modulatory intervention. A P-value of $<0.05$ was considered significant. All analyses were performed with GraphPad Prism 5.0 for Windows (GraphPad Software, Inc., La Jolla, California). 


\section{Results}

2 Effects of Th2 cytokines on rhinovirus-induced interferon production and rhinovirus

3

4

5

6 replication

To evaluate the effects of the Th2 status of the environment on rhinovirus-induced interferon (IFN) production, human bronchial epithelial cells (HBECs) and BEAS-2B cells were pre-treated with IL-4 and IL-13 prior to infection. Twenty-four-hour pre-treatment with IL-4 and IL-13 produced significant dose-dependent inhibition of rhinovirus-induced IFN- $\beta$ mRNA expression and IFN- $\beta$ protein release at 8 hrs after infection in both the BEAS-2B cell line (Supplementary Figure 1) and in HBECs (Figure 1A, 1C and 1E). Rhinovirus mediated induction of IFN- $\lambda$ mRNA expression was also diminished $8 \mathrm{hrs}$ after infection in both the BEAS-2B (Supplementary Figure 1) and HBECs (Figure 1B and 1D). IFN- $\lambda$ protein was undetectable in the cell culture supernatants of any of the experimental conditions assessed here. Neither IL-4 nor IL-13 had any modulatory effects on the rhinovirus-induced pro-inflammatory cytokine production, such as CXCL8 (Figure 1F). IL-2 (used as control; Figure $1 \mathrm{G}$ and $1 \mathrm{H}$ ) had no effect on rhinovirus-induced IFN induction. The inhibitory effect of Th2 cytokine pre-treatment on IFN production was observed at 8 but not 24 hrs after the infection (Figure 2A-D).

The impaired IFN expression following rhinovirus infection in the cell cultures that were pre-treated with Th2 cytokines was paralleled by increased rhinovirus replication in both the BEAS2B (data not shown) and HBECs (Figure 2E, 2F). Levels of IFN- $\beta$ and IFN- $\lambda$ mRNA and of $\underline{\text { rhinovirus vRNA were virtually undetectable (close to the lowest limit of detection) in uninfected }}$ cells and in cells stimulated only with Th2 cytokines (Figure 1 and 2).

\section{Effects of Th2 cytokines on rhinovirus-induced activation of transcription factors involved in} interferon production and signalling.

To investigate the mechanisms involved in the inhibitory effects of the Th2 cytokines on rhinovirus-induced IFN production, we evaluated the effects of IL-4 and IL-13 on rhinovirus- 
1 induced activation of the transcription factors involved in interferon production, such as nuclear

2 factor-kB (NF-kB) and IFN regulatory factor (IRF)-3 (19) $\underline{(24)}$, and STAT1, which is a transcription

3 factor that is activated by interferon-receptor engagement, and this activation leads to the

4 transcription of IFN-stimulated genes (20).(25). NF-kB, IRF-3 and STAT1 were activated 2 hrs

5 after rhinovirus infection (Figure 3A-C). In the BEAS-2B epithelial cells, 12-hrs pre-treatment with

6 IL-4 (50 ng/ml) and IL-13 (25 ng/ml) significantly inhibited rhinovirus-induced IRF3 activation and

7 subsequent STAT1 activation (Figure 3B and 3C) but also resulted in a slight increase of NF-kB

8 activation that was not statistically significant (Figure 3A).

9

10 Effects of antioxidants on Th2 cytokine-induced impairment of the innate immune response to 11 rhinovirus.

12 Pre-treatment with exogenous NAC $(10 \mathrm{mM}) 30 \mathrm{~min}$ before rhinovirus infection abolished

13 the inhibitory effect of the 24-hr pre-treatment with Th2 cytokines on rhinovirus-induced IRF-3

14 (Figure 4A) and STAT1 activations (Figure 4B) and restored the rhinovirus-induced expressions of 15 IFN- $\lambda$ (Figure 4C) and IFN- $\beta$ mRNA (Figure 4D).

16

17 Effects of Phosphoinositide 3-kinases (PI3K) on Th2 cytokine-induced impairment of the 18 innate immune response to rhinovirus. the Th-2 induced impairment of the innate immune response to rhinovirus (Figure 4E).

24 Effects of Th2 cytokines and oxidants on TLR3 expression.

25 TLR-3 it is one of the key molecule activated by double stranded RNA produced during 26 rhinovirus infection which in turn activates transcription factors such as nuclear factor (NF)-kB and 
1 IFN regulatory factor (IRF)-3/7 leading to the production of proinflammatory cytokines,

2 chemokines and antiviral molecules including interferons (26-30). Twenty-four-hour IL-4 pre-

3 treatment significantly inhibited the baseline expression of TLR3 in the respiratory epithelial cells

4 (Figure 5A). This inhibition was not affected by concomitant cell exposure to the antioxidant N-

5 acetyl cysteine (NAC, $10 \mathrm{mM}$; figure $5 \mathrm{~A})$.

6 The expression of TLR3 mRNA was evaluated in the nasal epithelial cells from atopic

7 rhinitis patients. Compared to the non-atopic healthy subjects, the expression of IL-4 mRNA was

8 significantly higher in the primary nasal cells obtained from patients with atopic rhinitis, which

9 confirms the Th2-related nature of the inflammatory process present in the upper airways of these

10 subjects (Figure 5B). Conversely, TLR3 mRNA expression was significantly lower in the primary

11 nasal cells obtained from patients with atopic rhinitis compared to those of healthy subjects (Figure

12 5C). Consistent with the latter finding, increased viral replication was observed in the primary

13 cultures of the nasal epithelial cells from the atopic subjects compared to those of the controls

14 (Figure 5D).

15

16 


\section{Discussion}

2 Asthma is a chronic inflammatory disorder of the airways that is typically, butalthough not

3

4 always, characterized by enhanced Th2-type inflammation (21).(31). In this study, we documented that Th2 cytokines (IL-4 and IL-13) impaired components of innate immunity, such as the production of types I (IFN- $\beta$ ) and III IFN (IFN- $\lambda$ ), in response to rhinovirus infection. The inhibitory effects of Th2 inflammation on interferon production can favour increased susceptibility to infections in asthmatic patients.

The airway epithelial layer is the natural site at which respiratory viral infections occur. Recent investigations have evaluated the crosstalk between Th2 inflammation and antivirat interferon production at the bronchial epithelial level. Moriwaki and colleagues found that Th2 (IL13)-deficient mice exhibit greater enhancements of IFN- $\lambda$ expression following intratracheal instillation of poly-IC (which mimicked viral infection) than wild-type mice, whereas IFN- $\lambda$ expression following poly IC is absent in the lungs of mice with allergen -induced asthma in which Th2 cytokines plays a central pathogenic role (8). Eosinophils are the effector cells of the Th2 inflammatory cascade. It has recently been shown that rhinovirus infection of bronchial epitheliat cells cocultured with eosinophils results in the impairment of interferon $\beta$ and $\lambda$ production and increases rhinovirus replication (9). On the other side, previous studies have reported that interferon $\lambda$ down-regulates the $\mathrm{Th} 2 \mathrm{inflammatory}$ response (22 25). Taken together, these data support the existence of a counter regulatory relationship between Th2 inflammation and the innate immune response.

The mechanisms by which Th2 inhibits virus-induced interferon production at the airway epithelial level remain largely unexplored. Double-stranded RNA (dsRNA) produced during viral infection and replication is an important stimulus of the host innate immune response. This dsRNA is recognized and engaged by TLR3, which in turn activates transcription factors, such as nuclear factor (NF) $\mathrm{kB}$ and IFN regulatory factor (IRF)-3/7, which lead to the production of proinflammatory cytokines, chemokines and antiviral molecules including interferons (26-28). 
Previous studies have shown that oxidative stress negatively interferes with intracellular interferon signalling, including IRF3 activation $(14,15)$, but can amplify the activation of the transcription factors involved in virus -induced interferon production and/or inflammation, such as NF $\mathrm{kB}(29)$. It has also been reported that the exposure of epithelial cells to IL -4 and IL -13 cytokines leads to increased intracellular oxidative burst (30-32). In this study, we found that the stimulation of the bronchial epithelial cell line BEAS-2B with Th2 inflammatory cytokines (IL-4 and IL 13) led to reduced baseline expression of TLR 3 via a mechanism that was not mediated by oxidants. Similar results have previously been shown in human intestinal epithelial cells (33). In accordance with previous observations (14), we also found that Th2 cytokines inhibited rhinovirus-induced IRF3 activation via a mechanism that can be modulated by antioxidants. Thus, the impaired IRF3 activation documented here might be the consequence of the Th2 mediated impairment of TLR 3 expression (which leads to impaired IRF3 activation) and also the consequence of a direct Th2 induced oxidant mediated effect. Interestingly, we showed for the first time in the present study reduced in vivo levels of TLR 3 associated with enhanced Th2 inflammation in the nasal epitheliat cells of atopic rhinitis patients compared to normal controls. Interestingly, recent in vivo observations suggest that the expression (34) and activity (35) of TLR3 are not impaired in the bronchial epithelial cells of mild asthmatic subjects compared to healthy subjects. These data might suggest that mechanisms other than those associated with the TLR pathways are involved in the impairment of interferon production in the bronchial epithelial cells of asthmatic subjects. It is possible than such impairments develop only in specific subgroups of patients, e.g., those with more severe asthma and those more prone to infections, in which $\mathrm{Th} 2$ inflammation is pronounced. It is also conceivable that impaired TLR 3 expression in the upper respiratory tract i.e nasal mucosa could be a mechanism that is responsible for increased susceptibility that is primarily compartmentalized to upper respiratory infections in Th2 - oriented diseases such as atopic rhinitis. The outcome of the interferon-activated Janus kinase (JAK) signal transducer and activator 

1 genes with antiviral properties. Specifically, STAT1 activation is a common mechanism of the

$\mathrm{NF}-\mathrm{kB}$ is a key element in the rhinovirus -induced inflammatory response and might also be involved in virus-induced interferon production. A recent study showed that rhinovirus-infected NF-kB p65-deficient mice exhibited reduced neutrophilic inflammation; however, interferon induction, antiviral responses and viral loads are unaffected (36). In our study, we found that IL-4 stimulation did not impair rhinovirus -induced NF $\mathrm{kB}$ activation. Taken together, these experimental data confirm that $\mathrm{NF}-\mathrm{kB}$ is required for pro-inflammatory responses, but its role in interferon induction by rhinoviruses is redundant, and the data also show that Th2 cytokines do not impair NF$\mathrm{kB}$ activation potentially explaining why $\mathrm{IL}-4$ and $\mathrm{IL}-13$ had no effect on CXCL 8 in our model system.

The mechanisms by which a Th2 immunologic pattern inhibits virus-induced interferon production at the airway epithelial level, i.e. at the primary site of respiratory viral infections, remain largely unexplored. Here we evaluated the effects of Th2 cytokines over TLR-3 molecule and STAT1, IRF3 and NF-kB transcription factors, i.e. some of the key steps involved in rhinovirus induced interferon production (26-30). In line with previous observations (14), we found that Th2 cytokines inhibited rhinovirusinduced IRF3 activation. We also found impaired activation of STAT1 following rhinovirus infection in the presence of Th2 cytokines. It has been previously reported that a) the exposure of epithelial cells to IL-4 and IL-13 cytokines leads to increased intracellular oxidative burst (32-34) 
and b) oxidative stress negatively interferes with intracellular interferon signalling, including IRF3 $\underline{\text { activation }(14,15) \text { and interferon-induced JAK-STAT activation and signalling (15). Interestingly, }}$

3 here we show that the antioxidant NAC restores rhinovirus-mediated activation of IRF3 and STAT1

4 and the downstream IFN- $\beta$ and IFN- $\lambda$ mRNA induction. These data suggest that the inhibition of

5 oxidative stress represents a possible pharmacological approach to potentiate the innate immune

6 responses to rhinovirus in a Th2 inflammatory milieu.

\section{Oxidative stress can also amplify the activation of the NF-kB transcription factors involved} in virus-induced interferon production and/or inflammation (35). A recent study showed that $\underline{\text { rhinovirus-infected NF-kB p65-deficient mice exhibited reduced neutrophilic inflammation, while }}$ interferon induction, antiviral responses and viral loads were unaffected (29). In our study we found that IL-4 stimulation did not impair rhinovirus-induced NF-kB activation, while it affected rhinovirus induced interferon induction. Taken together, these experimental data confirm that NF$\underline{\mathrm{kB} \text { is required for pro-inflammatory responses, but its role in interferon induction by rhinoviruses is }}$ not essential an may be redundant. The fact that Th2 cytokines do not impair NF-kB activation is consistent with IL-4 and IL-13 having no effect on CXCL-8 induction in our model.

The stimulation of the bronchial epithelial cell line BEAS-2B with Th2 inflammatory cytokines (IL-4 and IL-13) led to reduced baseline expression of TLR3 via a mechanism that was not mediated by oxidants. Similar results have previously been shown in human intestinal epithelial cells (36). Thus, the impaired IRF3 activation documented here might be the consequence of the $\underline{\text { Th2 } 2 \text { mediated impairment of TLR } 3 \text { expression (which leads to impaired IRF3 activation) and also }}$ the consequence of a direct Th2-induced oxidant-mediated effect. Interestingly, we showed for the first time in the present study reduced in vivo levels of TLR 3 associated with enhanced Th2 inflammation in the nasal epithelial cells of atopic rhinitis patients compared to normal controls. In $\underline{\text { line with these concepts, it has been recently shown that house dust mite (HDM)-sensitised mice }}$ have impaired rhinovirus-induced interferon production that is paralleled by a strong Th2-skewed inflammatory airway response (37). In addition, the pre-exposure of airway epithelial cells to HDM 
1 before rhinovirus infection deregulates TLR3-mediated production of cytokines and inflammatory mediators (38). Therefore HDM could suppress the IFN system either directly or via a Th-2 mediated pathway, the latter requiring further investigation given that IL-4/IL-13 signalling is quite distinct from HDM signalling. Interestingly, recent in vivo observations suggest that the expression (39) and activity (40) of TLR3 are not impaired in the bronchial epithelial cells of mild asthmatic subjects compared to healthy subjects. These data might suggest that mechanisms other than those associated with the TLR pathways are involved in the impairment of interferon production in the bronchial epithelial cells of asthmatic subjects. It is possible that such impairments favour increased susceptibility to infections in specific subgroups of patients, e.g., those with more severe asthma and/or those patients with a predominant Th2 airway inflammation where such impairment is expected to be more pronounced-. It is also conceivable that impaired TLR3 expression in the upper respiratory tract i.e nasal mucosa could be a mechanism that is responsible for increased susceptibility that is primarily compartmentalized to upper respiratory infections in Th2-oriented $\underline{\text { diseases such as atopic rhinitis. }}$

Finally, we recently found that asthmatic children, irrespective of atopic status, and atopic children, irrespective of the presence of asthma, exhibit impaired immune responses at the bronchial epithelial level in terms of type I (IFN- $\beta$ ) and type III (IFN- $\lambda$ ) production after rhinovirus infection.

8 Enhanced Th2-mediated airway inflammation is the common biological substrate between these children (7)(7). In this study, we documented that the development of a Th2 environment negatively affects the molecular mechanisms that govern the innate immune responses to viral infections. Indeed, TLR3 expression was found to be impaired in the epithelial cells of the nasal mucosa of atopic patients. In accordance with this concept, we observed increased viral replication associated 3 with increased IL-4 expression in the nasal mucosa of atopic rhinitis patients compared to normal subjects. These data confirmsupport the concept that impaired immune responses to viral infection are not exclusive tothe Th2 inflammation can dampen the anti-viral response and make the Th2 environment even without asthma but are shared with other Th2 -driven diseases-(e.g. allergic 
1 rhinitis)-) a more susceptible condition to viral infections. This concept is consistent with recent

2 observations that subjects with atopic diseases (including asthma, rhinitis and dermatitis)

3 experience more frequent upper and lower respiratory tract infections than do non-atopic controls

4 (37). The inhibition of oxidative stress represents a possible pharmacological approach to potentiate

5 the innate immune responses of these patients and to reduce their susceptibility to infections.(41). In

6 this scenario any pharmacological approach able to down-regulate Th2 inflammation has the

7 potential to recover a defective innate immune responses. Previous studies showed that: a) IL-4

8 intracellular signalling leads to the activation of PI3k (20) and b) inhibition of PI3k resulted in

9 attenuated Th2 inflammatory response in a mouse model of allergic asthma (17) and enhanced TLR

10 signalling $(19,42)$. Interestingly, in our study we found that the inhibition of PI3k restored the

11 inhibitory effect of $24 \mathrm{hr}$ pre-treatment with Th-2 cytokines on rhinovirus induced IRF-3 activation,

12 suggesting that the inhibition of phosphoinositide 3-kinases counteract the Th-2 induced

13 impairment of the innate immune response to rhinovirus.

14 In conclusion we showed that Th2 inflammation can dampen the anti-viral response and

15 increase susceptibility viral infections of Th2 driven immunological conditions. In our experimental

16 setting, pre-treatment with either antioxidants or inhibitors of PI3ks prevented the Th2-induced

17 impairment of innate immune response to rhinovirus infection. Further studies are needed to

18 elucidate more extensively at system biology level the complex interactions in the signalling

19 pathways that links Th2 inflammation to impaired immune response to infections. 


\section{Statement of contribution}

2 Marco Contoli and Kazuhiro Ito conceived, designed and supervised all the study and

3 experimental procedures; they directly contributed in the laboratory work and wrote the first draft

4 of the manuscript. Alberto Papi co-designed and co-supervised all the study and experimental

5 procedures and acts as guarantor for the studies. Donatella Poletti (DP) performed the nasal

6 brushings. Antonio Pastore supervised the work of DP and advised on the scientific aspects of the

7 study. Anna Padovani, Brunilda Marku and Giulia Gnesini performed the laboratory work and

8 were in charge of the biological sample management and processing. Antonio Spanevello,

9 Gaetano Caramori, Michael R Edwards, Luminita Stanciu and Sebastian L. Johnston advised

10 on the scientific aspects of the study and contributed in the manuscript finalization. Paolo Morelli

11 supervised the statistical analysis. All authors have approved the final version for publication.

\section{Disclosure statement}

14 Dr. Contoli reports grants from Chiesi, personal fees from Chiesi, personal fees from AstraZeneca, 15 personal fees from Boehringer Ingelheim, personal fees from Chiesi, personal fees from

16 Astrazeneca, personal fees from Novartis, personal fees from Menarini, personal fees from

17 Mundipharma, personal fees from Almirall, personal fees from Zambon, outside the submitted

18 work. Dr. Ito reports other from Pulmocide Ltd, outside the submitted work. Dr. Padovani has

19 nothing to disclose. Dr. Poletti has nothing to disclose. Dr. Marku has nothing to disclose. Dr.

20 Edwards has nothing to disclose. Dr. Stanciu has nothing to disclose. Dr. Gnesini has nothing to

21 disclose. Dr. Pastore has nothing to disclose. Dr. Spanevello has nothing to disclose. Dr. Morelli

22 has nothing to disclose. Dr. Johnston reports grants and personal fees from Centocor, grants and

23 personal fees from Sanofi Pasteur, grants and personal fees from GSK, grants and personal fees

24 from Chiesi, grants and personal fees from Boehringer Ingelheim, personal fees from Grünenthal,

25 grants and personal fees from Novartis, grants, personal fees and other from Synairgen, outside the

26 submitted work; In addition, Dr. Johnston has a patent Blair ED, Killington RA, Rowlands DJ, 
1 Clarke NJ, Johnston SL. Transgenic animal models of HRV with human ICAM-1 sequences. UK

2 patent application No. 02167 29.4, 18 July 2002 and International patent application No.

3 PCT/EP2003/007939, 17 July 2003. licensed, a patent Wark PA, Johnston SL, Holgate ST, Davies

4 DE. Anti-virus therapy for respiratory diseases. UK patent application No. GB $0405634.7,12$

5 March 2004. licensed, a patent Wark PA, Johnston SL, Holgate ST, Davies DE. Interferon-Beta for

6 Anti-Virus Therapy for Respiratory Diseases. International Patent Application No.

7 PCT/GB05/50031, 12 March 2004. licensed, a patent Wark PA, Johnston SL, Holgate ST, Davies

8 DE. The use of Interferon Lambda for the treatment and prevention of virally-induced exacerbation

9 in asthma and chronic pulmonary obstructive disease. UK patent application No. 0518425.4, 9

10 September 2005. licensed, a patent Wark PA, Johnston SL, Holgate ST, Davies DE. Anti-Virus

11 Therapy for Respiratory Diseases. US Patent Application - 11/517,763, Patent No.7569216,

12 National Phase of PCT/GB2005/050031, 04 August 2009. licensed, a patent Wark PA, Johnston

13 SL, Holgate ST, Davies DE. Interferon-beta for Anti-Virus Therapy for Respiratory Diseases.

14 European Patent Number 1734987, 5 May 2010. licensed, a patent Wark PA, Johnston SL, Holgate

15 ST, Davies DE. Anti-Virus Therapy for Respiratory Diseases (IFNb therapy) Hong Kong Patent

16 Number 1097181, 31 August 2010. licensed, a patent Wark PA, Johnston SL, Holgate ST, Davies

17 DE. Anti-Virus Therapy for Respiratory Diseases (IFNb therapy). Japanese Patent Number

18 4807526, 26 August 2011. licensed, a patent Wark PA, Johnston SL, Holgate ST, Davies DE.

19 Interferon-beta for Anti-Virus Therapy for Respiratory Diseases. New Hong Kong - Divisional

20 Patent Application No. 11100187.0, 10 January 2011. Licensed, and a patent Burdin N, Almond J,

21 Lecouturieir, V, Girerd-Chambaz Y, Guy, B, Bartlett N, Walton R, McLean G, Glanville N,

22 Johnston SL. Induction of cross-reactive cellular response against rhinovirus antigens European

23 Patent Number 13305152, 4 April 2013. pending. Dr. Caramori reports grants from AstraZeneca

24 Italy, grants and personal fees from Boehringer Ingelheim, grants and other from GlaxoSmithKline

25 Italy, grants from Menarini, grants from Almirall, outside the submitted work. Dr. Papi reports

26 grants, personal fees, non-financial support and other from Chiesi, grants, personal fees, non- 
1

2

3

4

5

6

7

8

9

10

11

12

13

14

15

16

17

18

19

20

21

22

23

24

25

26

27

28

29

30

31

32

33

34

35

36

37

38

39

40

41

42

43

44

45

46

47

48

49

50

51

52

53

54

55

56

57

58

59

60

1 financial support and other from Astrazeneca, grants, personal fees, non-financial support and other

2 from GlaxoSmithKline, grants, personal fees, non-financial support and other from Boehringer

3 Ingelheim, grants, personal fees, non-financial support and other from Merck Sharp \& Dohme,

4 personal fees and non-financial support from Menarini, personal fees and non-financial support

5 from Novartis, personal fees and non-financial support from Zambon, grants, personal fees, non-

6 financial support and other from Pfizer, grants, personal fees, non-financial support and other from

7 Takeda, grants, personal fees, non-financial support and other from Mundipharma, outside the

8 submitted work. 


\section{Figure legends}

2 Figure 1. Dose-response effects of 24-hr pre-treatment with Th2 cytokines (IL-4: panel A and B -

3 IL-13: panel C and D) on rhinovirus-induced interferon mRNA induction (IFN- $\beta$ : panel A and C

4 and IFN- $\lambda$ : panel B and D) in human bronchial epithelial cells (HBEC) of non-atopic, non-

5

6

7 cells and IL-4- or IL-13-treated cells; ${ }^{\wedge} \mathrm{p}<0.05$ vs. RV16 infected cells). Panel F: Effects of Th2

8 cytokines (IL-4: $50 \mathrm{ng} / \mathrm{ml}$ and IL-13: $25 \mathrm{ng} / \mathrm{ml}$ ) on rhinovirus-induced CXCL-8 production in

9 HBECs $(* p<0.01$ vs. untreated and uninfected cells and IL-4- or IL-13-treated cells). Effects of IL-2

10 on rhinovirus-induced IFN- $\beta$ mRNA (Panel G) and IFN- $\lambda$ mRNA (Panel H) in HBECs

$11 \quad\left({ }^{* * *} \mathrm{p}<0.001 ;{ }^{* *} \mathrm{p}<0.01 ;{ }^{*} \mathrm{p}<0.05 ; \mathrm{RV} 16\right.$ : rhinovirus 16; f-RV16: cells inoculated with virus stock

14 Figure 2. Time course of the effects of 24-hr pre-treatment with Th2 cytokines (IL-4 and IL-13) on

24 Figure 4. Effects of 24-hr pre-treatment with IL-4 $(50 \mathrm{ng} / \mathrm{ml})$ on rhinovirus (RV) 16-induced

25 interferon responsive factor 3 (IRF3; Panel A) and STAT1 (Panel B) activation in the presence or

26 absence of cell exposure to $\mathrm{N}$-acetylcysteine (NAC, $10 \mathrm{mM}) 30$ minutes prior to infection 
$1 \quad(* * \mathrm{p}<0.01 ; \mathrm{p}<0.05)$. Effects of $\mathrm{N}$-acetylcysteine (NAC, $10 \mathrm{mM}) 30$ minutes prior to infection on the

2 inhibitory effects of 24-hr pre-treatment with IL-4 $(50 \mathrm{ng} / \mathrm{ml})$ on rhinovirus (RV) 16-induced IFN- $\lambda$

3 mRNA in BEAS-2B cells (Panel C) and IFN- $\beta$ mRNA (Panel D) (ns: not significant; ${ }^{*} \mathrm{p}<0.05$ ).

(Panel E) Effects of phosphoinositide 3-kinases (PI3k) inhibitor LY294002 (3.3 uM) before

rhinovirus infection on the inhibitory effect of $24-\mathrm{hr}$ pre-treatment with IL-4 $(50 \mathrm{ng} / \mathrm{ml})$ on

rhinovirus (RV) 16-induced IRF-3 activation $\left(* \mathrm{p}<0.05\right.$ vs. untreated and uninfected cells; $\wedge^{\wedge} \mathrm{p}<0.05$

vs. rhinovirus (RV) 16-infected cells and vs cells infected with RV16 and exposed to LY294002)

(all panels $\mathrm{n}=5)$.

9

10 Figure 5. Panel A) Effects of 24-hr pre-treatment with Th2 cytokines on TLR3 mRNA expression in BEAS-2B cells in the presence or absence of cell exposure to $\mathrm{N}$-acetylcysteine- $(\mathrm{n}=5)$. The expression of TLR3 was evaluated by real-time RT-PCR, the results were normalized to GAPDH,

13 and the expression levels are represented as the fold-changes in expression vs. medium-treated cells

$14\left({ }^{*} p<0.05\right.$ vs. medium-treated cells). Panel B) Baseline IL-4 mRNA levels in the primary cell

15 cultures of epithelial cells of the nasal mucosae of non-atopic $(\mathrm{n}=6)$ and atopic $(\mathrm{n}=5)$ subjects. Panel

16 C) Baseline TLR3 mRNA levels in the primary cell cultures of epithelial cells of the nasal mucosae

17 of non-atopic $(\mathrm{n}=6)$ and atopic subjects- $(\mathrm{n}=5)$. D) Rhinovirus (RV) 16 vRNA levels $8 \mathrm{hr}$ after the

18 infection of primary nasal mucosa epithelial cells cultures of non-atopic $(\mathrm{n}=6)$ and atopic $(\mathrm{n}=5)$

19 subjects. 


\section{$1 \quad$ References}

2 1. Global Initiative for Asthma Global Strategy for Asthma Management and Prevention 2014.

$3 \quad$ Available from: wwwginasthmaorg

4 2. Edwards MR, Bartlett NW, Hussell T, Openshaw P, Johnston SL. The microbiology of asthma. Nature Reviews Microbiology 2012;10:459-471.

6 3. Corne J, Marshall C, Smith S, Schreiber J, Sanderson G, Holgate S et al. Frequency, severity,

9 4. Holt PG, Strickland DH. Interactions between innate and adaptive immunity in asthma

5. Hansel TT, Johnston SL, Openshaw PJ. ReviewMicrobes and mucosal immune responses in pathogenesis: new perspectives from studies on acute exacerbations. $J$ Allergy Clin Immunol asthma. The Lancet 2013;381:861-873.

16 7. Baraldo S, Contoli M, Bazzan E, Turato G, Padovani A, Marku B et al. Deficient antiviral immune responses in childhood: distinct roles of atopy and asthma. J Allergy Clin Immunol 2012;130:1307-1314.

8. Moriwaki A, Matsumoto K, Matsunaga Y, Fukuyama S, Matsumoto T, Kan-O K et al. IL-13 suppresses double-stranded RNA-induced IFN- $\lambda$ production in lung cells. Biochemical and Biophysical Research Communications 2011;404:922-927.

9. Mathur SK, Fichtinger PS, Kelly JT, Lee W-M, Gern JE, Jarjour NN. Interaction between allergy and innate immunity: model for eosinophil regulation of epithelial cell interferon expression. Ann Allergy Asthma Immunol 2013;111:25-31.

10. Beisswenger C, Kandler K, Hess C, Garn H, Felgentreff K, Wegmann M et al. Allergic airway inflammation inhibits pulmonary antibacterial host defense. $J$ Immunol 
$1 \quad 2006 ; 177: 1833-1837$.

2 11. Message SD, Laza-Stanca V, Mallia P, Parker HL, Zhu J, Kebadze T et al. Rhinovirus-

3 induced lower respiratory illness is increased in asthma and related to virus load and Th1/2

$4 \quad$ cytokine and IL-10 production. Proc Natl Acad Sci USA 2008;105:13562-13567.

5 12. Papi A, Papadopoulos NG, Stanciu LA, Bellettato CM, Pinamonti S, Degitz K et al.

Reducing agents inhibit rhinovirus-induced up-regulation of the rhinovirus receptor intercellular adhesion molecule-1 (ICAM-1) in respiratory epithelial cells. The FASEB Journal 2002;16:1934-1936.

9 13. Papi A, Contoli M, Gasparini P, Bristot L, Edwards MR, Chicca M et al. Role of xanthine 10

14. Kocic G, Sokolovic D, Jevtovic T, Veljkovic A, Kocic R, Nikolic G et al. Hyperglycemia, oxidative and nitrosative stress affect antiviral, inflammatory and apoptotic signaling of cultured thymocytes. Redox Rep 2010;15:179-184.

15. Di Bona D, Cippitelli M, Fionda C, Cammà C, Licata A, Santoni A et al. Oxidative stress inhibits IFN-alpha-induced antiviral gene expression by blocking the JAK-STAT pathway. $J$ Hepatol 2006;45:271-279.

16. Zhao W, Qi J, Wang L, Zhang M, Wang P, Gao C. LY294002 inhibits TLR3/4-mediated IFN-b production via inhibition of IRF3 activation with a PI3K-independent mechanism. FEBS Lett 2012;586:705-710.

17. Lee KS, Lee HK, Hayflick JS, Yong C Lee, Kamal D Puri. Inhibition of phosphoinositide 3kinase attenuates allergic airway inflammation and hyperresponsiveness in murine asthma model. The FASEB Journal 2006;20:455-465.

18. Cao W, Manicassamy S, Tang H, Kasturi SP, Pirani A, Murthy N et al. Toll-like receptormediated induction of type I interferon in plasmacytoid dendritic cells requires the rapamycin-sensitive PI(3)K-mTOR-p70S6K pathway. Nat Immunol 2008;9:1157-1164. 


\section{Fukao T, Koyasu S. PI3K and negative regulation of TLR signaling. Trends in Immunology}

2

3

4

5

6

7

8

9 2003;24:358-363.

20. Kelly-Welch AE. Interleukin-4 and Interleukin-13 Signaling Connections Maps. Science 2003;300:1527-1528.

21. Contoli M, Message SD, Laza-Stanca V, Edwards MR, Wark PAB, Bartlett NW et al. Role of deficient type III interferon-lambda production in asthma exacerbations. Nat Med 2006;12:1023-1026.

1722. Wark PAB, Johnston SL, Bucchieri F, Powell R, Puddicombe S, Laza-Stanca V et al. Asthmatic bronchial epithelial cells have a deficient innate immune response to infection with rhinovirus. $J$ Exp Med 2005;201:937-947.

1823. Papi A, Johnston S. Rhinovirus infection induces expression of its own receptor intercellular adhesion molecule 1 (ICAM-1) via increased NF-kappa B-mediated transcription. J Biol Chem 1999;274:9707-9720.

1924. Kennedy JL, Turner RB, Braciale T, Heymann PW, Borish L. Pathogenesis of rhinovirus infection. Current Opinion in Virology 2012;2:287-293.

2025. Rauch I, Müller M, Decker T. The regulation of inflammation by interferons and their STATs. JAKSTAT 2013;2:e23820.

21. Wenzel SE. Asthma: defining of the persistent adult phenotypes. Lancet 2006;368:804 813.

22. Srinivas S, Dai J, Eskdale J, Gallagher GE, Megiugorae NJ, Gallagher G. Interferon lambda1 (interleukin-29) preferentially down-regulates interleukin-13 over other T helper type 2 eytokine responses in vitro. Immunnology 2008;125:492-502.

23. Dai J, Megjugorac NJ, Gallagher GE, Yu RYL, Gallagher G. IFN lambdal (IL-29) inhibits GATA3 expression and suppresses Th2 responses in human naive and memory T cells. Blood 2009;113:5829-5838. 24. Koltsida O, Hausding M, Stavropoulos A, Koch S, Tzelepis G, Ubel C et al. IL 28A (IFN22) modulates lung DC function to promote $T h 1$ immune skewing and suppress allergic 


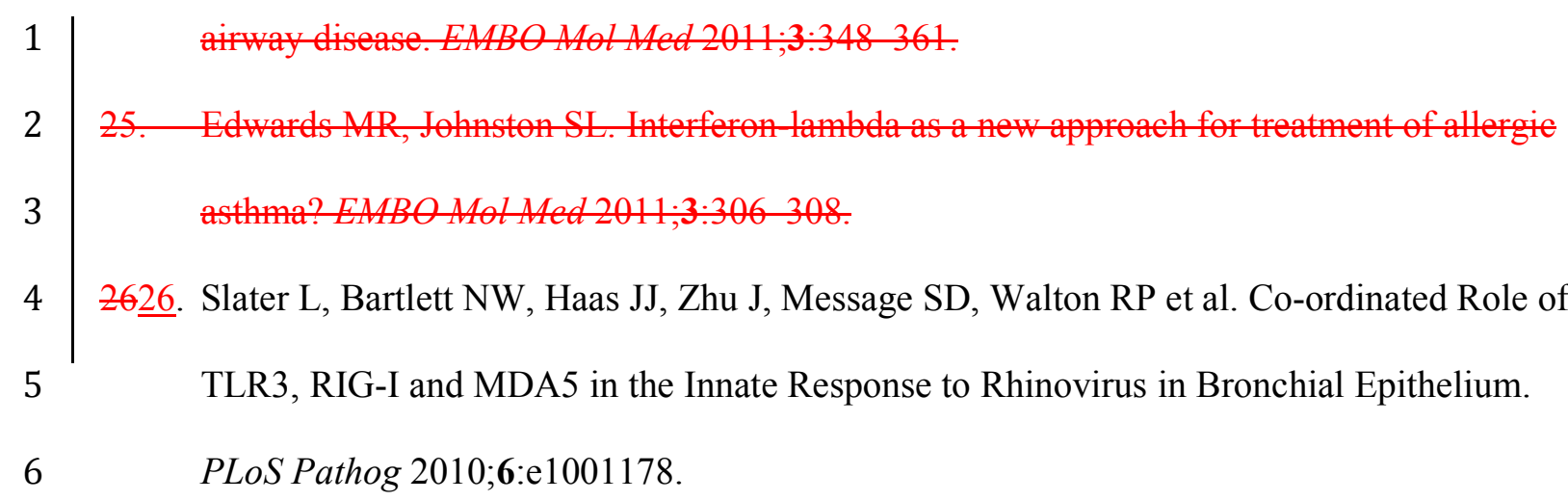

7 27. Hewson CA, Jardine A, Edwards MR, Laza-Stanca V, Johnston SL. Toll-like receptor 3 is 8 induced by and mediates antiviral activity against rhinovirus infection of human bronchial

$9 \quad$ epithelial cells. J Virol 2005;79:12273-12279.

10 2728. Wang Q, Nagarkar DR, Bowman ER, Schneider D, Gosangi B, Lei J et al. Role of double-

11 stranded RNA pattern recognition receptors in rhinovirus-induced airway epithelial cell

12 responses. J Immunol 2009;183:6989-6997.

13 2929. Bartlett NW, Slater L, Glanville N, Haas JJ, Caramori G, Casolari P et al. Defining critical

$14 \quad$ roles for NF-кB p65 and type I interferon in innate immunity to rhinovirus. EMBO Mol Med

15 Published Online First: 14 November 2012. doi:10.1002/emmm.201201650

16 30. Wang Q, Miller DJ, Bowman ER, Nagarkar DR, Schneider D, Zhao Y et al. MDA5 and

$17 \quad$ TLR3 initiate pro-inflammatory signaling pathways leading to rhinovirus-induced airways

$18 \quad$ inflammation and hyperresponsiveness. PLoS Pathog 2011;7:e1002070.

19 31. Wenzel SE. Asthma: defining of the persistent adult phenotypes. Lancet 2006;368:804-813.

20 32. Schnurr K, Borchert A, Kuhn H. Inverse regulation of lipid-peroxidizing and hydroperoxyl

lipid-reducing enzymes by interleukins 4 and 13. FASEB J 1999;13:143-154.

22 33. Lee Y. IL-4-induced Oxidative Stress Upregulates VCAM-1 Gene Expression in Human Endothelial Cells. Journal of Molecular and Cellular Cardiology 2001;33:83-94.

24 34. Brinckmann R, Topp MS, Zalán I, Heydeck D, Ludwig P, Kuhn H et al. Regulation of 15lipoxygenase expression in lung epithelial cells by interleukin-4. Biochem J 1996;318:305312. 
1 35. Koarai A, Sugiura H, Yanagisawa S, Ichikawa T, Minakata Y, Matsunaga K et al. Oxidative 2 Stress Enhances Toll-Like Receptor 3 Response to Double-Stranded RNA in Airway Epithelial Cells. Am J Respir Cell Mol Biol 2010;42:651-660.

4

306ㅜㄴ 31.3233. Mueller T, Terada T, Rosenberg IM, Shibolet O, Podolsky DK. Th2 Cytokines

5

Down-Regulate TLR Expression and Function in Human Intestinal Epithelial Cells. The

6 Journal of Immunology 2006;176:5805-5814.
7 3437. Rochlitzer S, Hoymann H-G, Müller M, Braun A, U-BIOPRED consortium. No exacerbation 8 but impaired anti-viral mechanisms in a rhinovirus-chronic allergic asthma mouse model.


Figure 1

The data are now plotted as box and whiskers
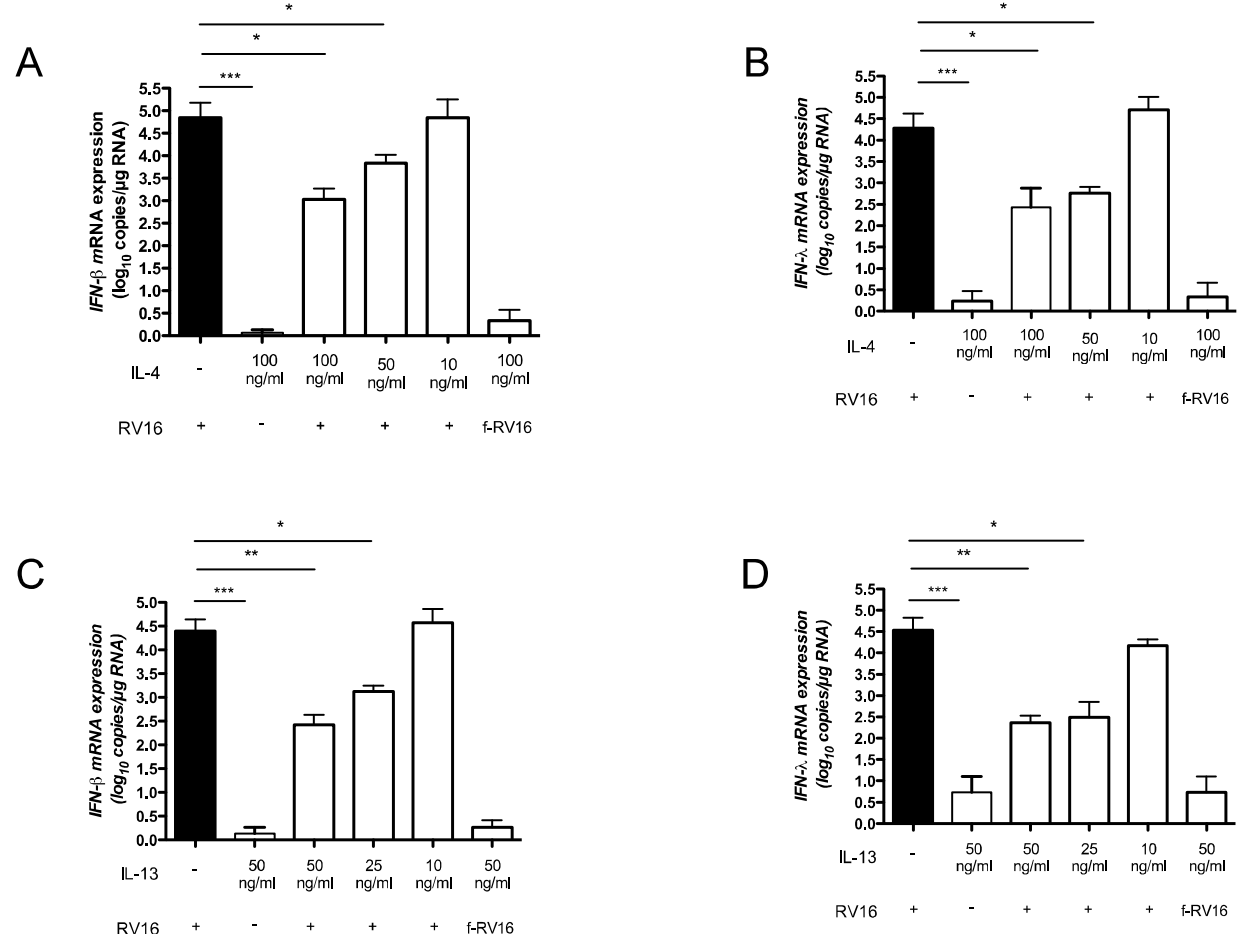

E
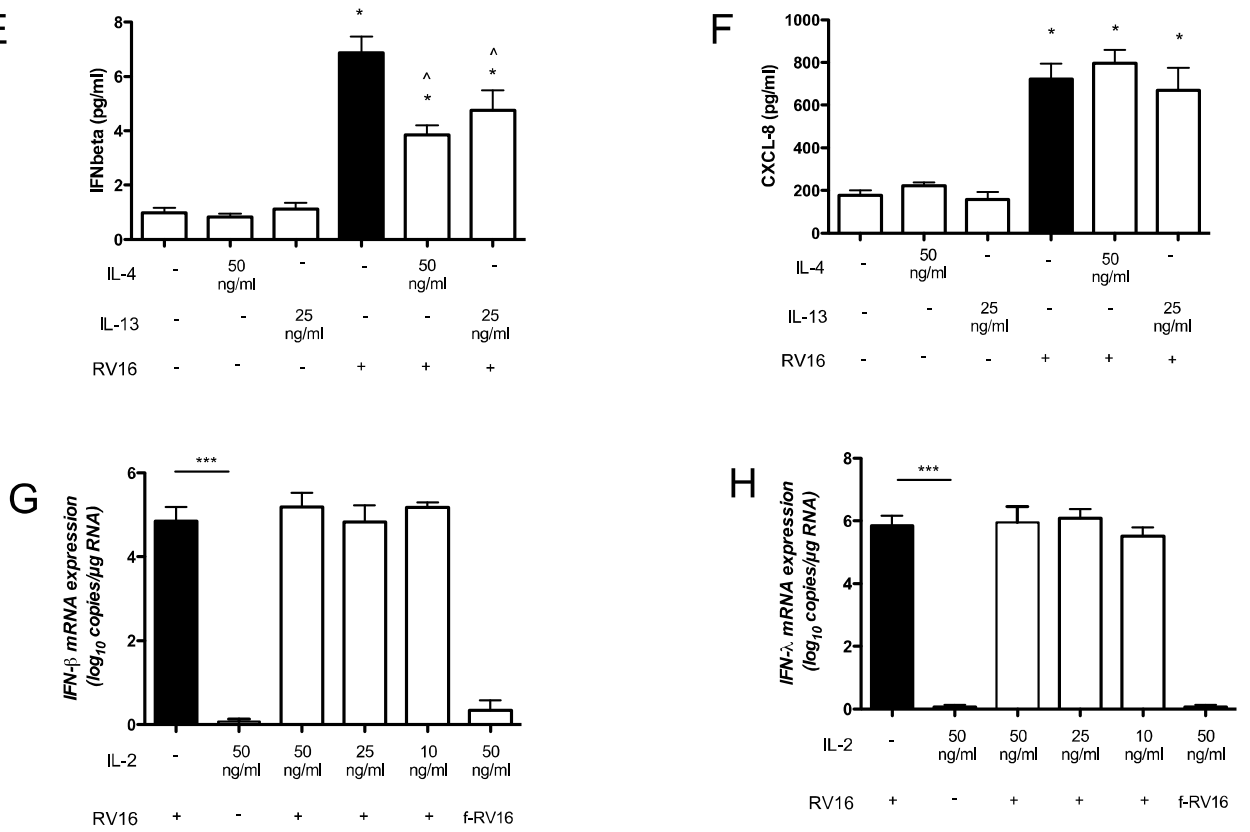
Figure 2

The data are now plotted as box and whiskers

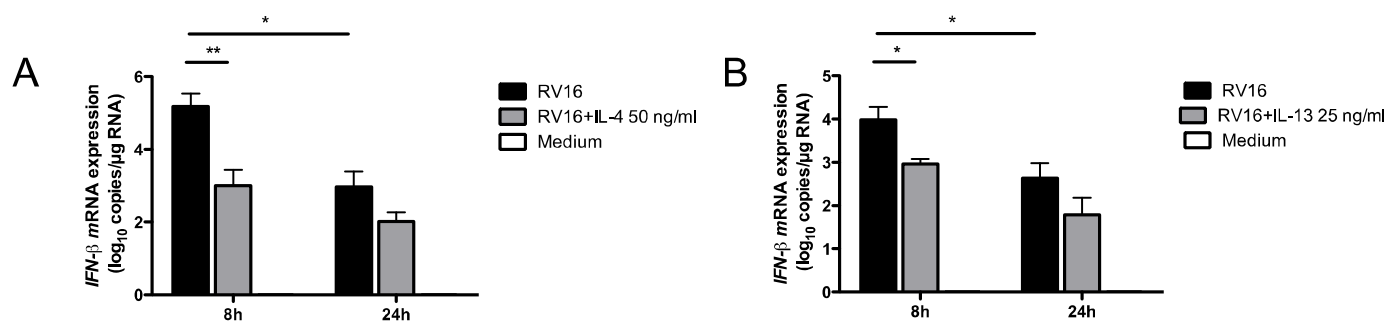

C

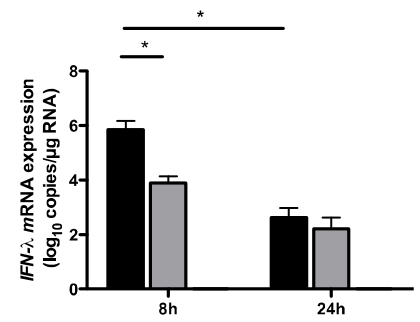

E

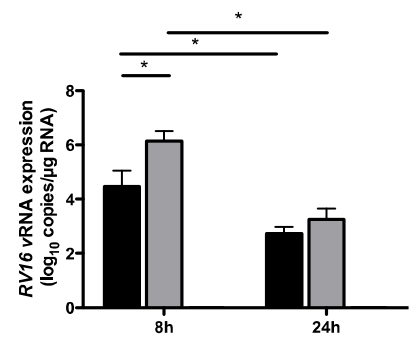

G

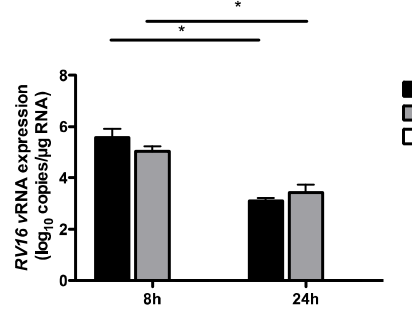

D

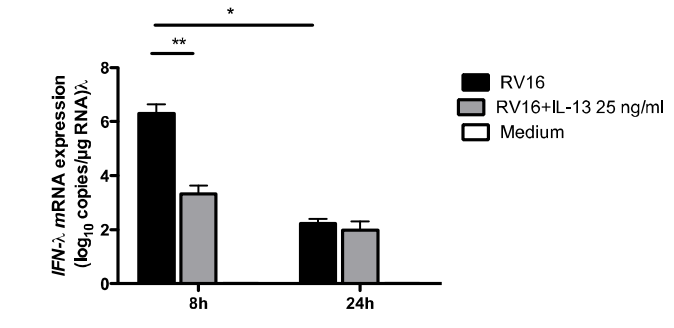

$\mathrm{F}$

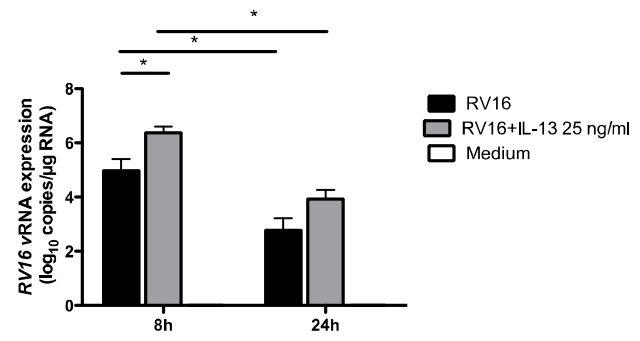

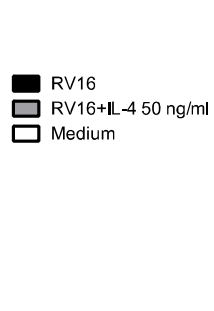

RV16

RV16+lL-2 $25 \mathrm{ng} / \mathrm{ml}$

RV16
RV16+lL-4 $50 \mathrm{ng} / \mathrm{ml}$

$\square$ Medium

42

44

45

46

48

49

50

51

52

53

54

55

56

57

58

59

60 
Figure 3 The data are now plotted as box and whiskers
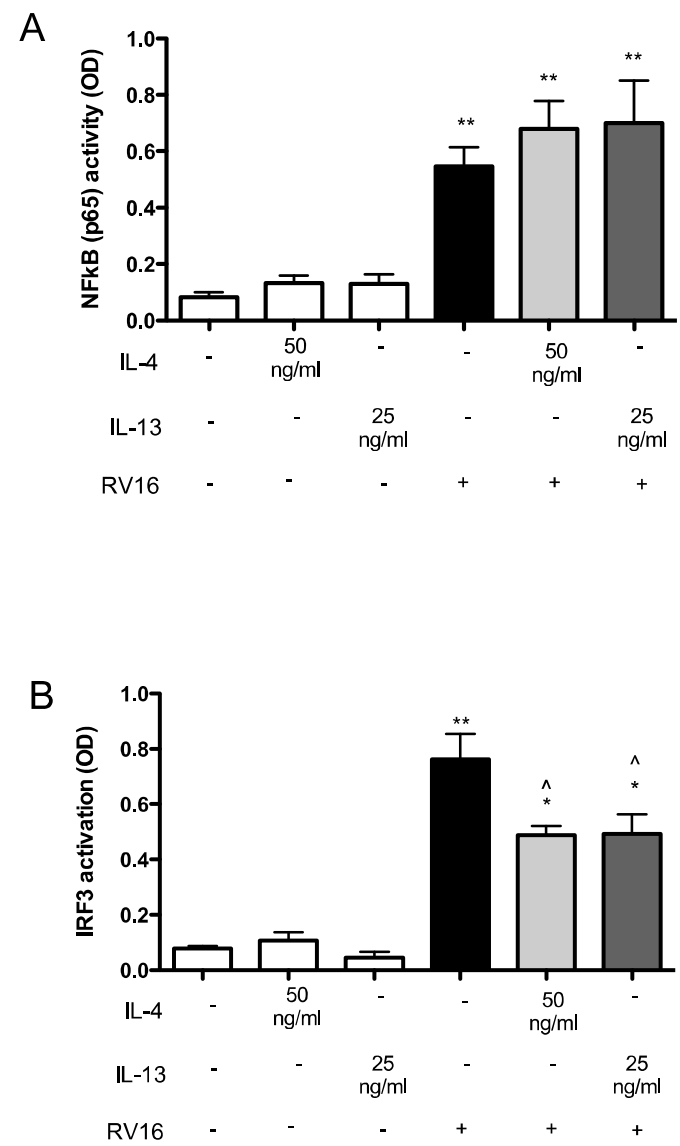

C

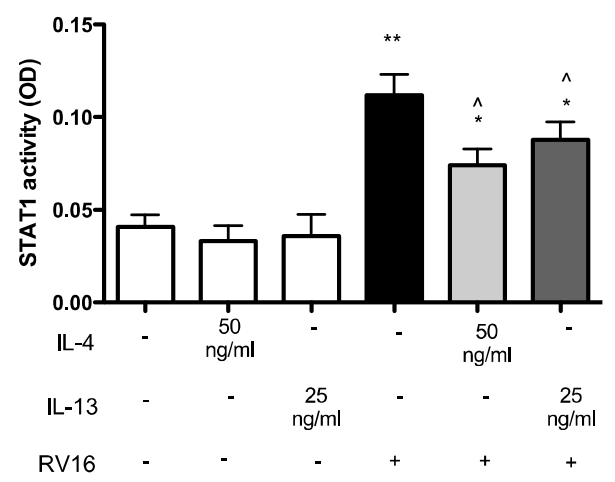


Figure 4 The data are now plotted as box and whiskers.

A new panel (E) providing new data has been added.

A

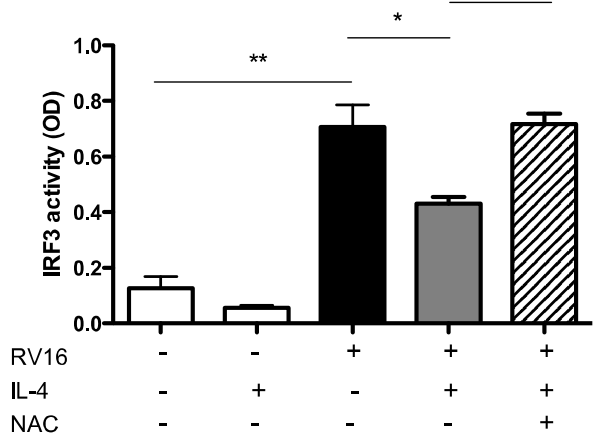

B

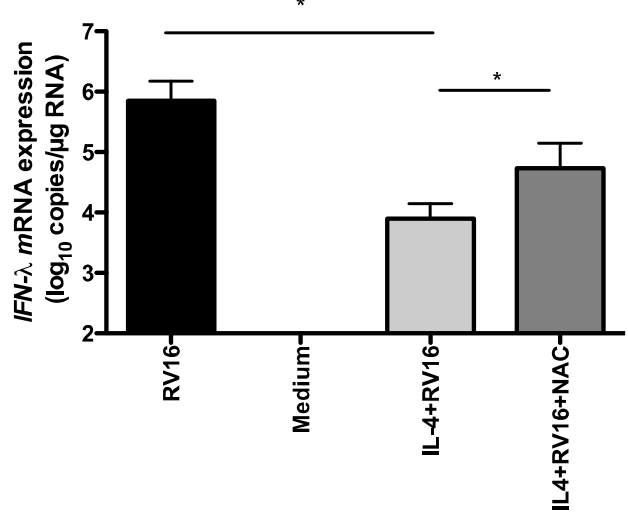

C

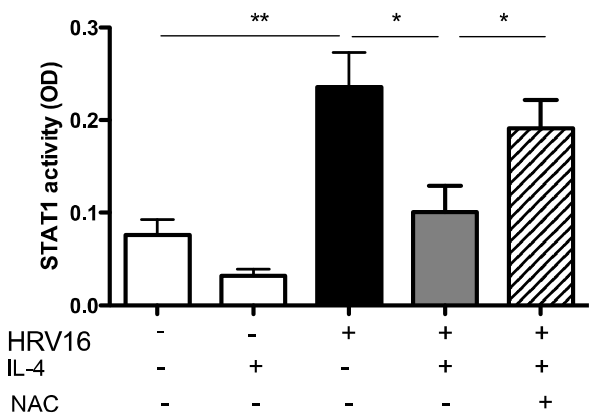

D

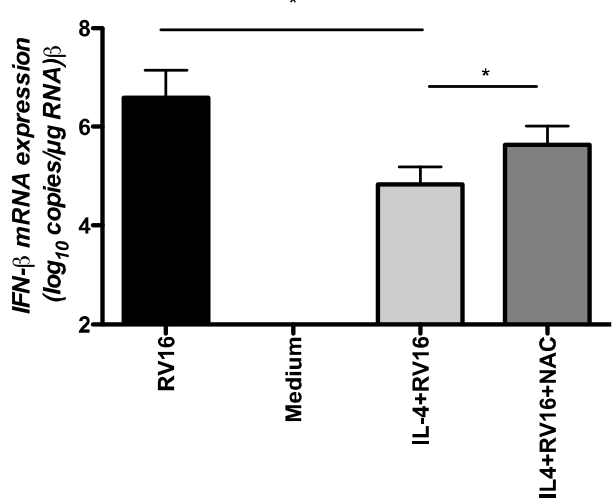


Figure 5

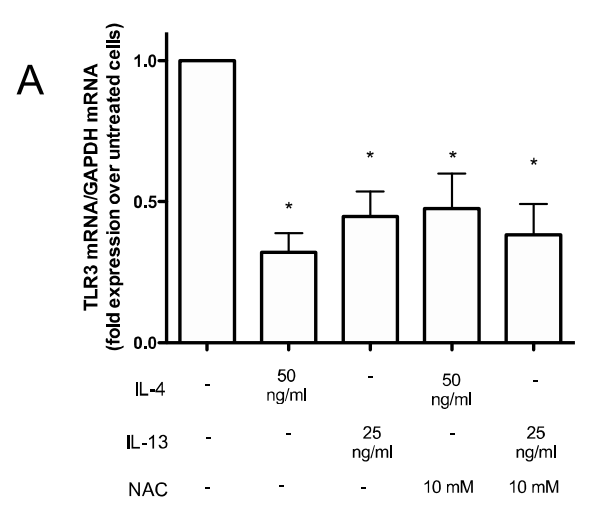

B

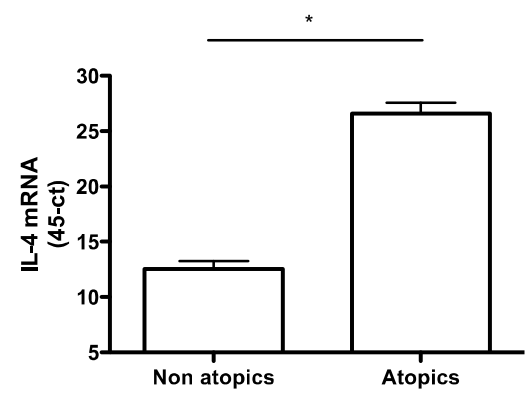

D

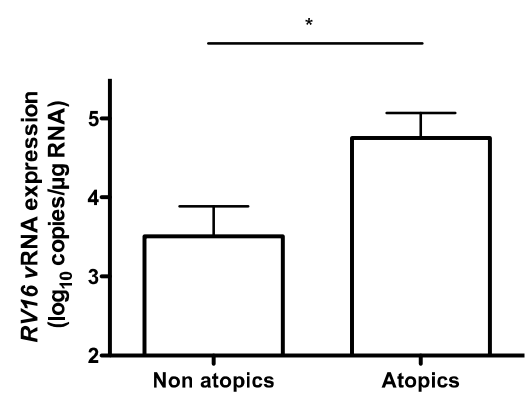

C

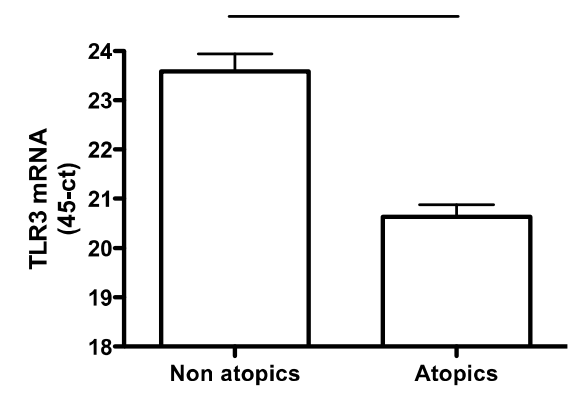


1 Th2-cytokines impair innate immune responses to rhinovirus in respiratory epithelial cells

2

3 Marco Contoli ${ }^{1}$, Kazuhiro Ito $^{2}$, Anna Padovani ${ }^{1}$, Donatella Poletti ${ }^{3}$, Brunilda Marku ${ }^{1}$, Michael R.

4 Edwards $^{4}$, Luminita A. Stanciu ${ }^{4}$, Giulia Gnesini ${ }^{1}$, Antonio Pastore ${ }^{3}$, Antonio Spanevello ${ }^{5}$, Paolo

5 Morelli $^{6}$, Sebastian L. Johnston ${ }^{4}$, Gaetano Caramori ${ }^{1}$, Alberto Papi ${ }^{1}$.

6

$7{ }^{1}$ Research Centre on Asthma and COPD, Department of Medical Sciences, University of Ferrara, 8 Italy

$9 \quad{ }^{2}$ Airway Disease, National Heath and Lung Institute, Imperial College, London, UK.

$10{ }^{3}$ ENT Unit, Department of Biomedical and Surgical Sciences, University of Ferrara, Italy

$11{ }^{4}$ Airway Disease Infection Section, National Heart and Lung Institute, Imperial College and MRC

12 and Asthma UK Centre in Allergic Mechanisms of Asthma, London, UK

$13{ }^{5}$ University of Insubria, Varese; Fondazione Maugeri, IRCCS, Tradate

$14{ }^{6}$ Cros NT, Verona, Italy.

15

16 Address correspondence to:

17 Marco Contoli, MD, PhD

18 Research Centre on Asthma and COPD, Department of Medical Sciences, University of Ferrara, 19 Italy

20 Via Savonarola 9, 44121 Ferrara, Italy

21 Tel: +390532236908

22 Fax: +390532210297

23 Email: ctm@unife.it 


\section{Page 35 of 63}

1

2

3

4

5

6

7

8

9

10

11

12

13

14

15

16

17

18

19

20

21

22

23

24

25

26

27

28

29

30

31

32

33

34

35

36

37

38

39

40

41

42

43

44

45

46

47

48

49

50

51

52

53

54

55

56

57

58

59

60
1 Word count (text): 2554

2 Key words: asthma, innate immunity, virus, Th2 inflammation, interferon.

3

4 


\section{Abstract (word count: 245)}

2 Background: Asthma and other Th2 inflammatory conditions have been associated with increased

3 susceptibility to viral infections. The mechanisms by which Th2 cytokines can influence immune

4 responses to infections are largely unknown.

5 Methods: We measured the effects of Th2 cytokines (IL-4 and IL-13) on bronchial epithelial cell

6 innate immune antiviral responses by assessing interferon (IFN- $\beta$ and IFN- $\lambda 1$ ) induction following

7 rhinovirus (RV)-16 infection. We also investigated the modulatory effects of Th2 cytokines on

8 Toll-like receptor (TLR)-3, interferon-responsive factor (IRF)-3, and nuclear factor (NF)-kB, i.e.

9 key molecules and transcription factors involved in the rhinovirus-induced interferon production

10 and inflammatory cascade. Pharmacological and redox modulation of these pathways was also

11 assessed.

12 Results: Th2 cytokines impaired RV16-induced interferon production, increased rhinovirus

13 replication and impaired TLR3 expression in bronchial epithelial cells. These results were

14 replicated in vivo: we found increased IL-4 mRNA levels in nasal epithelial cells from nasal

15 brushing of atopic rhinitis patients and a parallel reduction of TLR3 expression and increased RV16

16 replication compared to non-atopic subjects. Mechanistically, Th2 cytokines impaired RV-16

17 induced activation of IRF3, but had no effects on RV16-induced NF-kB activation in bronchial

18 epithelial cell cultures. $\mathrm{N}$-acetylcysteine and phosphoinositide 3-kinase (PI3k) inhibitor restored the

19 inhibitory effects of Th2 cytokines over RV-16 induced activation of IRF3.

20 Conclusions: IL-4 and IL-13, through inhibition of TLR3 expression and signalling (IRF-3), impair

21 immune response to RV-16 infection. These data suggest that $\mathrm{Th} 2$ conditions increase susceptibility

22 to infections and identify pharmacological approaches with potential to restore impaired immune

23 response in these conditions. 


\section{Introduction}

2

Asthma is a chronic disorder of the airways that is typically inflammatory in nature and

3 affects millions of children and adults (1).

Viral infections of the respiratory tract early in life are associated with an increased risk of

5 developing asthma later in life and are also the most frequent causes of asthma exacerbations in

6 both children and adults (2). Rhinoviruses are the respiratory virus type that is most frequently

7 detected during asthma exacerbations (3). The innate immune response is at the forefront of the

8 defence against respiratory infections.

9 Impaired innate immune responses have been reported to be a possible mechanism of

10 increased susceptibility to infections among asthmatic patients $(2,4,5)$. The molecular mechanisms

11 underlying such a deficiency are still largely unknown.

The cytokines produced by the Th2 subset of lymphocytes, such as IL-4 and IL-13, have

13 been proven to be important drivers of allergic airway inflammation in asthma, although a) the

14 mechanisms underlying their roles in the complex pathogenesis are still widely debated b) not all

15 asthmatic patients have a preponderant Th2 oriented inflammatory profile in the airways (6) nor

16 allergen driven clinical manifestations. We recently documented that in vivo Th2 inflammation is

17 associated with impaired ex vivo immune responses to rhinovirus infection in bronchial epithelial

18 cells from asthmatic children and also in cells from atopic children without any established clinical

19 manifestations of asthma (7). These data accord with previous in vitro (8-10) and in vivo data (11)

20 suggest that the Th2 inflammation influences the integrity of the innate immune responses and the

21 outcomes of infections. Thus, intercepting the mechanisms of Th2 interference upon innate immune

22 response may improve the ability of counteract the susceptibility to infections in these clinical

23 conditions.

24 Oxidative stress has previously been found to influence the molecular pathways that are

25 commonly involved in rhinovirus-induced intracellular signalling and proinflammatory activities

26 (12,13). Furthermore, it has been shown that oxidative stress can impair innate immune responses 
1 by interfering with the intracellular interferon signalling $(14,15)$. In addition, phosphoinositide 3-

2 kinases (PI3K) is a large family of intracellular signalling kinases involved in the both innate

3 immune response to infections and Th2 inflammation (16-20). Thus, modulation of the intracellular

4 redox state and of PI3k immunoregulatory activities represent potential pharmacological targets of

5 interference with the substrates of immunological and inflammatory responses to viral infections.

6 Here, we evaluated the effects of Th2 cytokines (IL-4 and IL-13) on innate immune

7 responses as assessed by type I (IFN- $\beta$ ) and type III (IFN- $\lambda 1$ ) interferon production against

8 rhinovirus infection in bronchial epithelial cells. We also evaluated the effects of Th2 cytokines

9 over key molecules (TLR-3) and transcription factors (IRF3 and NF-kB) involved in the innate

10 immune responses to rhinovirus and tested potential methods of pharmacological modulation. 


\section{Methods}

\section{Cell cultures and in vitro rhinovirus infections}

The immortalized human bronchial epithelial cell line BEAS-2B was obtained from the

4 American Type Culture Collection (Rockville, Md, USA) and cultured as previously described (21).

5 Primary human bronchial epithelial cells (HBECs) were obtained from bronchial brushings of non-

6 atopic, non-asthmatic and non-smoking subjects (who underwent bronchoscopy for clinical reasons

7 - Supplementary Table 1) and cultured as previously described $(7,21,22)$.

8 Primary epithelial cells of the nasal mucosae of five atopic rhinitis and six non-atopic

9 healthy non-smoker volunteers were harvested by nasal scraping and freshly cultured in BEG

10 medium (Supplementary Table 2). When confluent, total RNA was extract according to

11 manufacturer's instructions (Qiagen).

12 The demographic characteristics of the patients enrolled in the study and the experimental

13 conditions of the cell cultures and stimulations are detailed in the online supporting information and 14 in Supplementary Table 1 and 2.

15 The study was approved by the local ethics committee of the University Hospital of Ferrara, 16 and informed consent was obtained from each participant in accordance with the principles outlined 17 in the Declaration of Helsinki.

\section{Viral stocks}

Rhinovirus type 16 (RV16) was obtained from the Health Protection Agency Culture

Collections, Salisbury, United Kingdom and used for all of the experimental conditions described.

The virus was used at a multiplicity of infection (MOI) of 5 in all experiments (23).

\section{Quantitative TaqMan real-time RT-PCR}

Quantitative real-time PCR was performed with specific primers and probes for rhinovirus, 
1 detailed elsewhere $(7,21,22)$. Quantitative real-time PCR results were normalized to $18 \mathrm{~S}$ rRNA or

2 GAPDH expression (housekeeping genes). Interferon mRNA, CXCL8 mRNA, and viral RNA

3 (vRNA) expression were normalized to $18 \mathrm{~S}$ rRNA levels, compared with standard curves, and

4 expressed as $\log _{10}$ copy numbers per microgram of RNA. An arbitrary level equal to 1 copy of IFN-

5 beta, -lambda mRNA or vRNA was assigned if undetectable.

6

\section{$7 \quad$ Interferon and CXCL8 protein assays} previously detailed (7).

\section{Measurement of transcription factor activation}

\section{Statistical analyses}

The enzyme-linked immunosorbent assays (ELISA) used for the detections of IFN- $\beta$, IFN- $\lambda$, and CXCL8 levels in cell-culture supernatants were performed according to the manufacturers' instructions. The sensitivities, specificities, and sources for the individual ELISAs have been

Nuclear extracts were prepared from the BEAS2B cells using a nuclear protein extraction kit (Active Motif, Rixensart, Belgium). Activated NFkB, IRF3 and STAT1 in 10- $\mu$ g nuclear extracts were detected by evaluating their bindings to oligonucleotides targeting each binding site using ELISA-based assays (TransAM Transcription Factor Assay kits for NFkB, IRF3 and the STAT family; Active Motif, La Hulpe, Belgium) following the manufacturer's recommendations.

Comparisons between conditions were performed by means of paired or unpaired non parametric tests (Wilcoxon test or Mann-Whitney test respectively). After the evaluation of the effects of rhinovirus infection (e.g. on interferon induction and/or transcription factors activation), in case of multiple tests, paired comparisons were performed using a Hierarchical method to control for multiplicity based on concentration, timing or modulatory intervention. A P-value of $<0.05$ was considered significant. All analyses were performed with GraphPad Prism 5.0 for Windows 


\section{Page 41 of 63}

1

2

3

4

1 (GraphPad Software, Inc., La Jolla, California).

2

52

6
7

8

9

10

11

12

13

14

15

16

17

18

19

20

21

22

23

24

25

26

27

28

29

30

31

34

35

36

37

38

39

40

41

42

43

44

45

46

47

48

49

50

51

52

53

54

55

56

57

58

59

60 
1 Results

2 Effects of Th2 cytokines on rhinovirus-induced interferon production and rhinovirus

3 replication (IFN) production, human bronchial epithelial cells (HBECs) and BEAS-2B cells were pre-treated with IL-4 and IL-13 prior to infection. Twenty-four-hour pre-treatment with IL-4 and IL-13

7 produced significant dose-dependent inhibition of rhinovirus-induced IFN- $\beta$ mRNA expression and

8 IFN- $\beta$ protein release at 8 hrs after infection in both the BEAS-2B cell line (Supplementary Figure

9 1) and in HBECs (Figure 1A, 1C and 1E). Rhinovirus mediated induction of IFN- $\lambda$ mRNA

10 expression was also diminished $8 \mathrm{hrs}$ after infection in both the BEAS-2B (Supplementary Figure

11 1) and HBECs (Figure 1B and 1D). IFN- $\lambda$ protein was undetectable in the cell culture supernatants

12 of any of the experimental conditions assessed here. Neither IL-4 nor IL-13 had any modulatory

13 effects on the rhinovirus-induced pro-inflammatory cytokine production, such as CXCL8 (Figure

14 1F). IL-2 (used as control; Figure $1 \mathrm{G}$ and $1 \mathrm{H}$ ) had no effect on rhinovirus-induced IFN induction.

15 The inhibitory effect of Th2 cytokine pre-treatment on IFN production was observed at 8 but not 24

16 hrs after the infection (Figure 2A-D).

17 The impaired IFN expression following rhinovirus infection in the cell cultures that were

18 pre-treated with Th2 cytokines was paralleled by increased rhinovirus replication in both the BEAS-

19 2B (data not shown) and HBECs (Figure 2E, 2F). Levels of IFN- $\beta$ and IFN- $\lambda$ mRNA and of

20 rhinovirus vRNA were virtually undetectable (close to the lowest limit of detection) in uninfected

21 cells and in cells stimulated only with Th2 cytokines (Figure 1 and 2).

22

23

24

\section{Effects of Th2 cytokines on rhinovirus-induced activation of transcription factors involved in} interferon production and signalling.

To investigate the mechanisms involved in the inhibitory effects of the Th2 cytokines on rhinovirus-induced IFN production, we evaluated the effects of IL-4 and IL-13 on rhinovirus- 
1 induced activation of the transcription factors involved in interferon production, such as nuclear

2 factor-kB (NF-kB) and IFN regulatory factor (IRF)-3 (24), and STAT1, which is a transcription

3 factor that is activated by interferon-receptor engagement, and this activation leads to the

4 transcription of IFN-stimulated genes (25). NF-kB, IRF-3 and STAT1 were activated $2 \mathrm{hrs}$ after

5 rhinovirus infection (Figure 3A-C). In the BEAS-2B epithelial cells, 12-hrs pre-treatment with IL-4

$6 \quad(50 \mathrm{ng} / \mathrm{ml})$ and IL-13 (25 ng/ml) significantly inhibited rhinovirus-induced IRF3 activation and

7 subsequent STAT1 activation (Figure 3B and 3C) but also resulted in a slight increase of NF-kB

8 activation that was not statistically significant (Figure 3A).

9

Effects of antioxidants on Th2 cytokine-induced impairment of the innate immune response to 11 rhinovirus.

Pre-treatment with exogenous NAC $(10 \mathrm{mM}) 30 \mathrm{~min}$ before rhinovirus infection abolished the inhibitory effect of the 24-hr pre-treatment with Th2 cytokines on rhinovirus-induced IRF-3

(Figure 4A) and STAT1 activations (Figure 4B) and restored the rhinovirus-induced expressions of

\section{Effects of Phosphoinositide 3-kinases (PI3K) on Th2 cytokine-induced impairment of the} innate immune response to rhinovirus.

We found that pre-treatment with the phosphoinositide 3-kinases (PI3k) inhibitor LY294002 (3.3 uM) before rhinovirus infection restored the inhibitory effect of Th-2 cytokines on rhinovirus induced IRF-3 activation, suggesting that the inhibition of phosphoinositide 3-kinases counteract the Th-2 induced impairment of the innate immune response to rhinovirus (Figure 4E).

\section{Effects of Th2 cytokines and oxidants on TLR3 expression.}

TLR-3 it is one of the key molecule activated by double stranded RNA produced during rhinovirus infection which in turn activates transcription factors such as nuclear factor (NF)-kB and 
1 IFN regulatory factor (IRF)-3/7 leading to the production of proinflammatory cytokines,

2 chemokines and antiviral molecules including interferons (26-30). Twenty-four-hour IL-4 pre-

3 treatment significantly inhibited the baseline expression of TLR3 in the respiratory epithelial cells

4 (Figure 5A). This inhibition was not affected by concomitant cell exposure to the antioxidant N-

5 acetyl cysteine (NAC, $10 \mathrm{mM}$; figure $5 \mathrm{~A})$.

6 The expression of TLR3 mRNA was evaluated in the nasal epithelial cells from atopic

7 rhinitis patients. Compared to the non-atopic healthy subjects, the expression of IL-4 mRNA was

8 significantly higher in the primary nasal cells obtained from patients with atopic rhinitis, which

9 confirms the Th2-related nature of the inflammatory process present in the upper airways of these

10 subjects (Figure 5B). Conversely, TLR3 mRNA expression was significantly lower in the primary

11 nasal cells obtained from patients with atopic rhinitis compared to those of healthy subjects (Figure

12 5C). Consistent with the latter finding, increased viral replication was observed in the primary

13 cultures of the nasal epithelial cells from the atopic subjects compared to those of the controls

14 (Figure 5D).

15

16 


\section{Discussion}

2

Asthma is a chronic inflammatory disorder of the airways that is typically, although not

3 always, characterized by enhanced Th2-type inflammation (31). In this study, we documented that

4 Th2 cytokines (IL-4 and IL-13) impaired components of innate immunity, such as the production of

5 types I (IFN- $\beta$ ) and III IFN (IFN- $\lambda$ ), in response to rhinovirus infection.

The mechanisms by which a Th2 immunologic pattern inhibits virus-induced interferon

7 production at the airway epithelial level, i.e. at the primary site of respiratory viral infections,

8 remain largely unexplored. Here we evaluated the effects of Th2 cytokines over TLR-3 molecule

9 and STAT1, IRF3 and NF-kB transcription factors, i.e. some of the key steps involved in rhinovirus

10 induced interferon production (26-30).

11 In line with previous observations (14), we found that Th2 cytokines inhibited rhinovirus-

12 induced IRF3 activation. We also found impaired activation of STAT1 following rhinovirus

13 infection in the presence of Th2 cytokines. It has been previously reported that a) the exposure of

14 epithelial cells to IL-4 and IL-13 cytokines leads to increased intracellular oxidative burst (32-34)

15 and b) oxidative stress negatively interferes with intracellular interferon signalling, including IRF3

16 activation $(14,15)$ and interferon-induced JAK-STAT activation and signalling (15). Interestingly,

17 here we show that the antioxidant NAC restores rhinovirus-mediated activation of IRF3 and STAT1

18 and the downstream IFN- $\beta$ and IFN- $\lambda$ mRNA induction. These data suggest that the inhibition of

19 oxidative stress represents a possible pharmacological approach to potentiate the innate immune

20 responses to rhinovirus in a Th2 inflammatory milieu.

21 Oxidative stress can also amplify the activation of the NF-kB transcription factors involved

22 in virus-induced interferon production and/or inflammation (35). A recent study showed that

23 rhinovirus-infected NF-kB p65-deficient mice exhibited reduced neutrophilic inflammation, while

24 interferon induction, antiviral responses and viral loads were unaffected (29). In our study we found

25 that IL-4 stimulation did not impair rhinovirus-induced NF-kB activation, while it affected

26 rhinovirus induced interferon induction. Taken together, these experimental data confirm that NF- 
$1 \mathrm{kB}$ is required for pro-inflammatory responses, but its role in interferon induction by rhinoviruses is

2 not essential an may be redundant. The fact that Th2 cytokines do not impair NF-kB activation is

3 consistent with IL-4 and IL-13 having no effect on CXCL-8 induction in our model.

The stimulation of the bronchial epithelial cell line BEAS-2B with Th2 inflammatory

5 cytokines (IL-4 and IL-13) led to reduced baseline expression of TLR3 via a mechanism that was

6 not mediated by oxidants. Similar results have previously been shown in human intestinal epithelial

7 cells (36). Thus, the impaired IRF3 activation documented here might be the consequence of the

8 Th2 mediated impairment of TLR3 expression (which leads to impaired IRF3 activation) and also

9 the consequence of a direct Th2-induced oxidant-mediated effect. Interestingly, we showed for the

10 first time in the present study reduced in vivo levels of TLR3 associated with enhanced Th2

11 inflammation in the nasal epithelial cells of atopic rhinitis patients compared to normal controls. In

12 line with these concepts, it has been recently shown that house dust mite (HDM)-sensitised mice

13 have impaired rhinovirus-induced interferon production that is paralleled by a strong Th2-skewed

14 inflammatory airway response (37). In addition, the pre-exposure of airway epithelial cells to HDM

15 before rhinovirus infection deregulates TLR3-mediated production of cytokines and inflammatory

16 mediators (38). Therefore HDM could suppress the IFN system either directly or via a Th-2

17 mediated pathway, the latter requiring further investigation given that IL-4/IL-13 signalling is quite

18 distinct from HDM signalling. Interestingly, recent in vivo observations suggest that the expression

19 (39) and activity (40) of TLR3 are not impaired in the bronchial epithelial cells of mild asthmatic

20 subjects compared to healthy subjects. These data might suggest that mechanisms other than those

21 associated with the TLR pathways are involved in the impairment of interferon production in the

22 bronchial epithelial cells of asthmatic subjects. It is possible that such impairments favour increased

23 susceptibility to infections in specific subgroups of patients, e.g., those with more severe asthma

24 and/or those patients with a predominant Th2 airway inflammation where such impairment is

25 expected to be more pronounced-. It is also conceivable that impaired TLR3 expression in the upper

26 respiratory tract i.e nasal mucosa could be a mechanism that is responsible for increased 
1 susceptibility that is primarily compartmentalized to upper respiratory infections in Th2-oriented

2 diseases such as atopic rhinitis.

3 Finally, we recently found that asthmatic children, irrespective of atopic status, and atopic

4 children, irrespective of the presence of asthma, exhibit impaired immune responses at the bronchial

5 epithelial level in terms of type I (IFN- $\beta$ ) and type III (IFN- $\lambda$ ) production after rhinovirus infection.

6 Enhanced Th2-mediated airway inflammation is the common biological substrate between these

7 children (7). In this study, we documented that the development of a Th2 environment negatively

8 affects the molecular mechanisms that govern the innate immune responses to viral infections.

9 Indeed, TLR3 expression was found to be impaired in the epithelial cells of the nasal mucosa of

10 atopic patients. In accordance with this concept, we observed increased viral replication associated

11 with increased IL-4 expression in the nasal mucosa of atopic rhinitis patients compared to normal

12 subjects. These data support the concept that the Th2 inflammation can dampen the anti-viral

13 response and make the Th2 environment even without asthma (e.g. allergic rhinitis) a more

14 susceptible condition to viral infections. This concept is consistent with recent observations that

15 subjects with atopic diseases (including asthma, rhinitis and dermatitis) experience more frequent

16 upper and lower respiratory tract infections than do non-atopic controls (41). In this scenario any

17 pharmacological approach able to down-regulate Th2 inflammation has the potential to recover a

18 defective innate immune responses. Previous studies showed that: a) IL-4 intracellular signalling

19 leads to the activation of PI3k (20) and b) inhibition of PI3k resulted in attenuated Th2

20 inflammatory response in a mouse model of allergic asthma (17) and enhanced TLR signalling

$21(19,42)$. Interestingly, in our study we found that the inhibition of PI3k restored the inhibitory effect

22 of $24 \mathrm{hr}$ pre-treatment with Th-2 cytokines on rhinovirus induced IRF-3 activation, suggesting that

23 the inhibition of phosphoinositide 3-kinases counteract the Th-2 induced impairment of the innate

24 immune response to rhinovirus.

25 In conclusion we showed that Th2 inflammation can dampen the anti-viral response and

26 increase susceptibility viral infections of Th2 driven immunological conditions. In our experimental 
1 setting, pre-treatment with either antioxidants or inhibitors of PI3ks prevented the Th2-induced

2 impairment of innate immune response to rhinovirus infection. Further studies are needed to

3 elucidate more extensively at system biology level the complex interactions in the signalling

4 pathways that links Th2 inflammation to impaired immune response to infections.

5 


\section{Statement of contribution}

2 Marco Contoli and Kazuhiro Ito conceived, designed and supervised all the study and

3 experimental procedures; they directly contributed in the laboratory work and wrote the first draft

4 of the manuscript. Alberto Papi co-designed and co-supervised all the study and experimental

5 procedures and acts as guarantor for the studies. Donatella Poletti (DP) performed the nasal

6 brushings. Antonio Pastore supervised the work of DP and advised on the scientific aspects of the

7 study. Anna Padovani, Brunilda Marku and Giulia Gnesini performed the laboratory work and

8 were in charge of the biological sample management and processing. Antonio Spanevello,

9 Gaetano Caramori, Michael R Edwards, Luminita Stanciu and Sebastian L. Johnston advised 10 on the scientific aspects of the study and contributed in the manuscript finalization. Paolo Morelli 11 supervised the statistical analysis. All authors have approved the final version for publication.

\section{Disclosure statement}

14 Dr. Contoli reports grants from Chiesi, personal fees from Chiesi, personal fees from AstraZeneca, 15 personal fees from Boehringer Ingelheim, personal fees from Chiesi, personal fees from

16 Astrazeneca, personal fees from Novartis, personal fees from Menarini, personal fees from

17 Mundipharma, personal fees from Almirall, personal fees from Zambon, outside the submitted

18 work. Dr. Ito reports other from Pulmocide Ltd, outside the submitted work. Dr. Padovani has

19 nothing to disclose. Dr. Poletti has nothing to disclose. Dr. Marku has nothing to disclose. Dr.

20 Edwards has nothing to disclose. Dr. Stanciu has nothing to disclose. Dr. Gnesini has nothing to

21 disclose. Dr. Pastore has nothing to disclose. Dr. Spanevello has nothing to disclose. Dr. Morelli

22 has nothing to disclose. Dr. Johnston reports grants and personal fees from Centocor, grants and

23 personal fees from Sanofi Pasteur, grants and personal fees from GSK, grants and personal fees

24 from Chiesi, grants and personal fees from Boehringer Ingelheim, personal fees from Grünenthal,

25 grants and personal fees from Novartis, grants, personal fees and other from Synairgen, outside the

26 submitted work; In addition, Dr. Johnston has a patent Blair ED, Killington RA, Rowlands DJ, 
1 Clarke NJ, Johnston SL. Transgenic animal models of HRV with human ICAM-1 sequences. UK

2 patent application No. 02167 29.4, 18 July 2002 and International patent application No.

3 PCT/EP2003/007939, 17 July 2003. licensed, a patent Wark PA, Johnston SL, Holgate ST, Davies

4 DE. Anti-virus therapy for respiratory diseases. UK patent application No. GB $0405634.7,12$

5 March 2004. licensed, a patent Wark PA, Johnston SL, Holgate ST, Davies DE. Interferon-Beta for

6 Anti-Virus Therapy for Respiratory Diseases. International Patent Application No.

7 PCT/GB05/50031, 12 March 2004. licensed, a patent Wark PA, Johnston SL, Holgate ST, Davies

8 DE. The use of Interferon Lambda for the treatment and prevention of virally-induced exacerbation

9 in asthma and chronic pulmonary obstructive disease. UK patent application No. 0518425.4, 9

10 September 2005. licensed, a patent Wark PA, Johnston SL, Holgate ST, Davies DE. Anti-Virus

11 Therapy for Respiratory Diseases. US Patent Application - 11/517,763, Patent No.7569216,

12 National Phase of PCT/GB2005/050031, 04 August 2009. licensed, a patent Wark PA, Johnston

13 SL, Holgate ST, Davies DE. Interferon-beta for Anti-Virus Therapy for Respiratory Diseases.

14 European Patent Number 1734987, 5 May 2010. licensed, a patent Wark PA, Johnston SL, Holgate

15 ST, Davies DE. Anti-Virus Therapy for Respiratory Diseases (IFNb therapy) Hong Kong Patent

16 Number 1097181, 31 August 2010. licensed, a patent Wark PA, Johnston SL, Holgate ST, Davies

17 DE. Anti-Virus Therapy for Respiratory Diseases (IFNb therapy). Japanese Patent Number

18 4807526, 26 August 2011. licensed, a patent Wark PA, Johnston SL, Holgate ST, Davies DE.

19 Interferon-beta for Anti-Virus Therapy for Respiratory Diseases. New Hong Kong - Divisional

20 Patent Application No. 11100187.0, 10 January 2011. Licensed, and a patent Burdin N, Almond J,

21 Lecouturieir, V, Girerd-Chambaz Y, Guy, B, Bartlett N, Walton R, McLean G, Glanville N,

22 Johnston SL. Induction of cross-reactive cellular response against rhinovirus antigens European

23 Patent Number 13305152, 4 April 2013. pending. Dr. Caramori reports grants from AstraZeneca

24 Italy, grants and personal fees from Boehringer Ingelheim, grants and other from GlaxoSmithKline

25 Italy, grants from Menarini, grants from Almirall, outside the submitted work. Dr. Papi reports

26 grants, personal fees, non-financial support and other from Chiesi, grants, personal fees, non- 
1

2

3

4

5

6

7

8

9

10

11

1 financial support and other from Astrazeneca, grants, personal fees, non-financial support and other

2 from GlaxoSmithKline, grants, personal fees, non-financial support and other from Boehringer

3 Ingelheim, grants, personal fees, non-financial support and other from Merck Sharp \& Dohme,

4 personal fees and non-financial support from Menarini, personal fees and non-financial support

5 from Novartis, personal fees and non-financial support from Zambon, grants, personal fees, non-

6 financial support and other from Pfizer, grants, personal fees, non-financial support and other from

7 Takeda, grants, personal fees, non-financial support and other from Mundipharma, outside the 8 submitted work. 


\section{Figure legends}

2 Figure 1. Dose-response effects of 24-hr pre-treatment with Th2 cytokines (IL-4: panel A and B -

3 IL-13: panel C and D) on rhinovirus-induced interferon mRNA induction (IFN- $\beta$ : panel A and C

4 and IFN- $\lambda$ : panel B and D) in human bronchial epithelial cells (HBEC) of non-atopic, non-

5 asthmatic subjects. Panel E: Effects of 24-hr pre-treatment with Th2 cytokines (IL-4 and IL-13) on

6 rhinovirus (RV) 16-induced IFN- $\beta$ production in HBECs $\left({ }^{*} \mathrm{p}<0.01\right.$ vs. untreated and uninfected

7 cells and IL-4- or IL-13-treated cells; ${ }^{\wedge} \mathrm{p}<0.05$ vs. RV16 infected cells). Panel F: Effects of Th2

8 cytokines (IL-4: $50 \mathrm{ng} / \mathrm{ml}$ and IL-13: $25 \mathrm{ng} / \mathrm{ml}$ ) on rhinovirus-induced CXCL-8 production in

9 HBECs $(* p<0.01$ vs. untreated and uninfected cells and IL-4- or IL-13-treated cells). Effects of IL-2

10 on rhinovirus-induced IFN- $\beta$ mRNA (Panel G) and IFN- $\lambda$ mRNA (Panel H) in HBECs

$11 \quad\left(* * * \mathrm{p}<0.001 ;{ }^{* *} \mathrm{p}<0.01 ;{ }^{*} \mathrm{p}<0.05 ; \mathrm{RV} 16\right.$ : rhinovirus 16; f-RV16: cells inoculated with virus stock

12 from which the virus had been removed by molecular weight filtration) (all panels $n=6$ ).

14 Figure 2. Time course of the effects of 24-hr pre-treatment with Th2 cytokines (IL-4 and IL-13) on

15 rhinovirus-induced IFN- $\beta$ and IFN- $\lambda$ mRNA induction and rhinovirus replication in human

16 bronchial epithelial cells (HBECs). $\left({ }^{* *} \mathrm{p}<0.01 ; * \mathrm{p}<0.05\right)$ (all panels $\left.\mathrm{n}=6\right)$.

17

18 Figure 3. Effects of 24-hr pre-treatment with Th2 cytokines (IL-4: $50 \mathrm{ng} / \mathrm{ml}$ and IL-13: $25 \mathrm{ng} / \mathrm{ml}$ )

19 on rhinovirus-induced nuclear factor (NF)-kB (Panel A), interferon responsive factor 3 (IRF3; Panel

20 B) and STAT1 (Panel C) activation in BEAS-2b cell $(* * p<0.01$ and $* \mathrm{p}<0.05$ vs. untreated and

21 uninfected cells and IL-4- or IL-13-treated cells; ${ }^{\wedge} \mathrm{p}<0.05$ vs. rhinovirus (RV) 16-infected cells) (all

22 panels $n=4)$.

24 Figure 4. Effects of 24-hr pre-treatment with IL-4 (50 ng/ml) on rhinovirus (RV) 16-induced

25 interferon responsive factor 3 (IRF3; Panel A) and STAT1 (Panel B) activation in the presence or

26 absence of cell exposure to $\mathrm{N}$-acetylcysteine (NAC, $10 \mathrm{mM}) 30$ minutes prior to infection 
$1 \quad(* * \mathrm{p}<0.01 ; \mathrm{p}<0.05)$. Effects of $\mathrm{N}$-acetylcysteine (NAC, $10 \mathrm{mM}) 30$ minutes prior to infection on the

2 inhibitory effects of $24-\mathrm{hr}$ pre-treatment with IL-4 $(50 \mathrm{ng} / \mathrm{ml})$ on rhinovirus (RV) 16 -induced IFN- $\lambda$

3 mRNA in BEAS-2B cells (Panel C) and IFN- $\beta$ mRNA (Panel D) (ns: not significant; *p<0.05).

4 (Panel E) Effects of phosphoinositide 3-kinases (PI3k) inhibitor LY294002 (3.3 uM) before

5 rhinovirus infection on the inhibitory effect of 24-hr pre-treatment with IL-4 $(50 \mathrm{ng} / \mathrm{ml})$ on

6 rhinovirus (RV) 16-induced IRF-3 activation ( ${ }^{*} \mathrm{p}<0.05$ vs. untreated and uninfected cells; ${ }^{\wedge} \mathrm{p}<0.05$

7 vs. rhinovirus (RV) 16-infected cells and vs cells infected with RV16 and exposed to LY294002)

8 (all panels $\mathrm{n}=5)$.

9

10 Figure 5. Panel A) Effects of 24-hr pre-treatment with Th2 cytokines on TLR3 mRNA expression

11 in BEAS-2B cells in the presence or absence of cell exposure to $\mathrm{N}$-acetylcysteine $(\mathrm{n}=5)$. The

12 expression of TLR3 was evaluated by real-time RT-PCR, the results were normalized to GAPDH,

13 and the expression levels are represented as the fold-changes in expression vs. medium-treated cells

$14(* \mathrm{p}<0.05$ vs. medium-treated cells). Panel B) Baseline IL-4 mRNA levels in the primary cell

15 cultures of epithelial cells of the nasal mucosae of non-atopic $(n=6)$ and atopic $(n=5)$ subjects. Panel

16 C) Baseline TLR3 mRNA levels in the primary cell cultures of epithelial cells of the nasal mucosae

17 of non-atopic $(\mathrm{n}=6)$ and atopic subjects $(\mathrm{n}=5)$. D) Rhinovirus (RV) 16 vRNA levels $8 \mathrm{hr}$ after the

18 infection of primary nasal mucosa epithelial cells cultures of non-atopic $(n=6)$ and atopic $(n=5)$

19 subjects. 


\section{$1 \quad$ References}

2 1. Global Initiative for Asthma Global Strategy for Asthma Management and Prevention 2014.

$3 \quad$ Available from: wwwginasthmaorg

4 2. Edwards MR, Bartlett NW, Hussell T, Openshaw P, Johnston SL. The microbiology of asthma. Nature Reviews Microbiology 2012;10:459-471.

6 3. Corne J, Marshall C, Smith S, Schreiber J, Sanderson G, Holgate S et al. Frequency, severity,

9 4. Holt PG, Strickland DH. Interactions between innate and adaptive immunity in asthma

5. Hansel TT, Johnston SL, Openshaw PJ. ReviewMicrobes and mucosal immune responses in pathogenesis: new perspectives from studies on acute exacerbations. $J$ Allergy Clin Immunol asthma. The Lancet 2013;381:861-873.

16 7. Baraldo S, Contoli M, Bazzan E, Turato G, Padovani A, Marku B et al. Deficient antiviral immune responses in childhood: distinct roles of atopy and asthma. J Allergy Clin Immunol 2012;130:1307-1314.

8. Moriwaki A, Matsumoto K, Matsunaga Y, Fukuyama S, Matsumoto T, Kan-O K et al. IL-13 suppresses double-stranded RNA-induced IFN- $\lambda$ production in lung cells. Biochemical and Biophysical Research Communications 2011;404:922-927.

9. Mathur SK, Fichtinger PS, Kelly JT, Lee W-M, Gern JE, Jarjour NN. Interaction between allergy and innate immunity: model for eosinophil regulation of epithelial cell interferon expression. Ann Allergy Asthma Immunol 2013;111:25-31.

10. Beisswenger C, Kandler K, Hess C, Garn H, Felgentreff K, Wegmann M et al. Allergic airway inflammation inhibits pulmonary antibacterial host defense. $J$ Immunol 
2006;177:1833-1837.

2 11. Message SD, Laza-Stanca V, Mallia P, Parker HL, Zhu J, Kebadze T et al. Rhinovirusinduced lower respiratory illness is increased in asthma and related to virus load and Th1/2 cytokine and IL-10 production. Proc Natl Acad Sci USA 2008;105:13562-13567.

12. Papi A, Papadopoulos NG, Stanciu LA, Bellettato CM, Pinamonti S, Degitz K et al. Reducing agents inhibit rhinovirus-induced up-regulation of the rhinovirus receptor intercellular adhesion molecule-1 (ICAM-1) in respiratory epithelial cells. The FASEB Journal 2002;16:1934-1936.

13. Papi A, Contoli M, Gasparini P, Bristot L, Edwards MR, Chicca M et al. Role of xanthine oxidase activation and reduced glutathione depletion in rhinovirus induction of inflammation in respiratory epithelial cells. J Biol Chem 2008;283:28595-28606.

14. Kocic G, Sokolovic D, Jevtovic T, Veljkovic A, Kocic R, Nikolic G et al. Hyperglycemia, oxidative and nitrosative stress affect antiviral, inflammatory and apoptotic signaling of cultured thymocytes. Redox Rep 2010;15:179-184.

15. Di Bona D, Cippitelli M, Fionda C, Cammà C, Licata A, Santoni A et al. Oxidative stress inhibits IFN-alpha-induced antiviral gene expression by blocking the JAK-STAT pathway. $J$ Hepatol 2006;45:271-279.

16. Zhao W, Qi J, Wang L, Zhang M, Wang P, Gao C. LY294002 inhibits TLR3/4-mediated IFN-b production via inhibition of IRF3 activation with a PI3K-independent mechanism. FEBS Lett 2012;586:705-710.

17. Lee KS, Lee HK, Hayflick JS, Yong C Lee, Kamal D Puri. Inhibition of phosphoinositide 3kinase attenuates allergic airway inflammation and hyperresponsiveness in murine asthma model. The FASEB Journal 2006;20:455-465.

18. Cao W, Manicassamy S, Tang H, Kasturi SP, Pirani A, Murthy N et al. Toll-like receptormediated induction of type I interferon in plasmacytoid dendritic cells requires the rapamycin-sensitive PI(3)K-mTOR-p70S6K pathway. Nat Immunol 2008;9:1157-1164. 
1 19. Fukao T, Koyasu S. PI3K and negative regulation of TLR signaling. Trends in Immunology

2

4

5

6

7

8

9

10

11

12

13

14

15

16

17

18 2003;24:358-363.

20. Kelly-Welch AE. Interleukin-4 and Interleukin-13 Signaling Connections Maps. Science 2003;300:1527-1528.

21. Contoli M, Message SD, Laza-Stanca V, Edwards MR, Wark PAB, Bartlett NW et al. Role of deficient type III interferon-lambda production in asthma exacerbations. Nat Med 2006;12:1023-1026.

22. Wark PAB, Johnston SL, Bucchieri F, Powell R, Puddicombe S, Laza-Stanca V et al. Asthmatic bronchial epithelial cells have a deficient innate immune response to infection with rhinovirus. J Exp Med 2005;201:937-947.

23. Papi A, Johnston S. Rhinovirus infection induces expression of its own receptor intercellular adhesion molecule 1 (ICAM-1) via increased NF-kappa B-mediated transcription. $J$ Biol Chem 1999;274:9707-9720.

24. Kennedy JL, Turner RB, Braciale T, Heymann PW, Borish L. Pathogenesis of rhinovirus infection. Current Opinion in Virology 2012;2:287-293.

25. Rauch I, Müller M, Decker T. The regulation of inflammation by interferons and their STATs. JAKSTAT 2013;2:e23820.

26. Slater L, Bartlett NW, Haas JJ, Zhu J, Message SD, Walton RP et al. Co-ordinated Role of TLR3, RIG-I and MDA5 in the Innate Response to Rhinovirus in Bronchial Epithelium. PLoS Pathog 2010;6:e1001178.

27. Hewson CA, Jardine A, Edwards MR, Laza-Stanca V, Johnston SL. Toll-like receptor 3 is induced by and mediates antiviral activity against rhinovirus infection of human bronchial epithelial cells. J Virol 2005;79:12273-12279.

28. Wang Q, Nagarkar DR, Bowman ER, Schneider D, Gosangi B, Lei J et al. Role of doublestranded RNA pattern recognition receptors in rhinovirus-induced airway epithelial cell responses. J Immunol 2009;183:6989-6997. 
1 29. Bartlett NW, Slater L, Glanville N, Haas JJ, Caramori G, Casolari P et al. Defining critical roles for NF-кB p65 and type I interferon in innate immunity to rhinovirus. EMBO Mol Med Published Online First: 14 November 2012. doi:10.1002/emmm.201201650

4 30. Wang Q, Miller DJ, Bowman ER, Nagarkar DR, Schneider D, Zhao Y et al. MDA5 and TLR3 initiate pro-inflammatory signaling pathways leading to rhinovirus-induced airways inflammation and hyperresponsiveness. PLoS Pathog 2011;7:e1002070.

33. Lee Y. IL-4-induced Oxidative Stress Upregulates VCAM-1 Gene Expression in Human Endothelial Cells. Journal of Molecular and Cellular Cardiology 2001;33:83-94.

34. Brinckmann R, Topp MS, Zalán I, Heydeck D, Ludwig P, Kuhn H et al. Regulation of 15lipoxygenase expression in lung epithelial cells by interleukin-4. Biochem J 1996;318:305312.

35. Koarai A, Sugiura H, Yanagisawa S, Ichikawa T, Minakata Y, Matsunaga K et al. Oxidative Stress Enhances Toll-Like Receptor 3 Response to Double-Stranded RNA in Airway Epithelial Cells. Am J Respir Cell Mol Biol 2010;42:651-660.

36. Mueller T, Terada T, Rosenberg IM, Shibolet O, Podolsky DK. Th2 Cytokines DownRegulate TLR Expression and Function in Human Intestinal Epithelial Cells. The Journal of Immunology 2006;176:5805-5814.

37. Rochlitzer S, Hoymann H-G, Müller M, Braun A, U-BIOPRED consortium. No exacerbation but impaired anti-viral mechanisms in a rhinovirus-chronic allergic asthma mouse model. Clin Sci 2014;126:55-65.

38. Golebski K, Luiten S, van Egmond D, de Groot E, Röschmann KIL, Fokkens WJ et al. High Degree of Overlap between Responses to a Virus and to the House Dust Mite Allergen in Airway Epithelial Cells. PLoS ONE 2014;9:e87768. 
1 39. Parsons KS, Hsu AC, Wark PAB. TLR3 and MDA5 signalling, although not expression, is

2 impaired in asthmatic epithelial cells in response to rhinovirus infection. Clin Exp Allergy

$32013 ; 44: 91-101$.

4 40. Sykes A, Edwards MR, Macintyre J, Del Rosario A, Gielen V, Haas J et al. TLR3, TLR4 and

5 TLRs7-9 Induced Interferons Are Not Impaired in Airway and Blood Cells in Well

$6 \quad$ Controlled Asthma. PLoS ONE 2013;8:e65921.

7 41. Rantala A, Jaakkola JJK, Jaakkola MS. Respiratory Infections in Adults with Atopic Disease

$8 \quad$ and IgE Antibodies to Common Aeroallergens. PLoS ONE 2013;8:e68582.

9 42. Aksoy E, Vanden Berghe W, Detienne S, Amraoui Z, Fitzgerald KA, Haegeman G et al.

10 Inhibition of phosphoinositide 3-kinase enhances TRIF-dependent NF- $\mathrm{BB}$ activation and

11 IFN- $\beta$ synthesis downstream of Toll-like receptor 3 and 4. Eur J Immunol 2005;35:2200-

2209.

13 
Figure 1
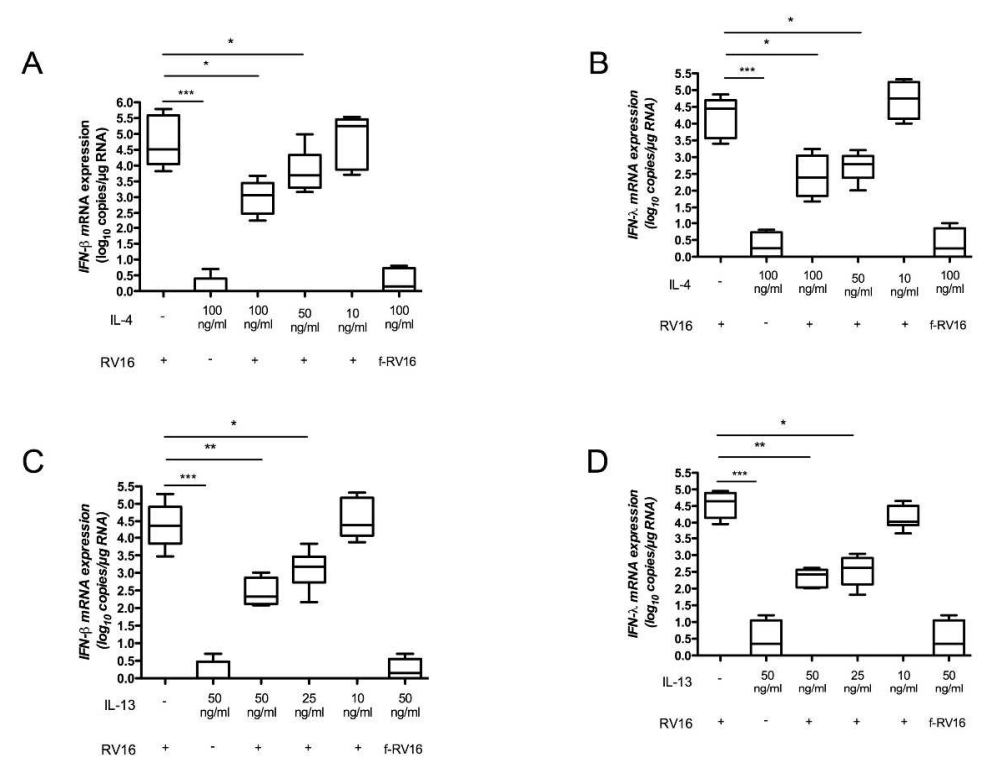

E
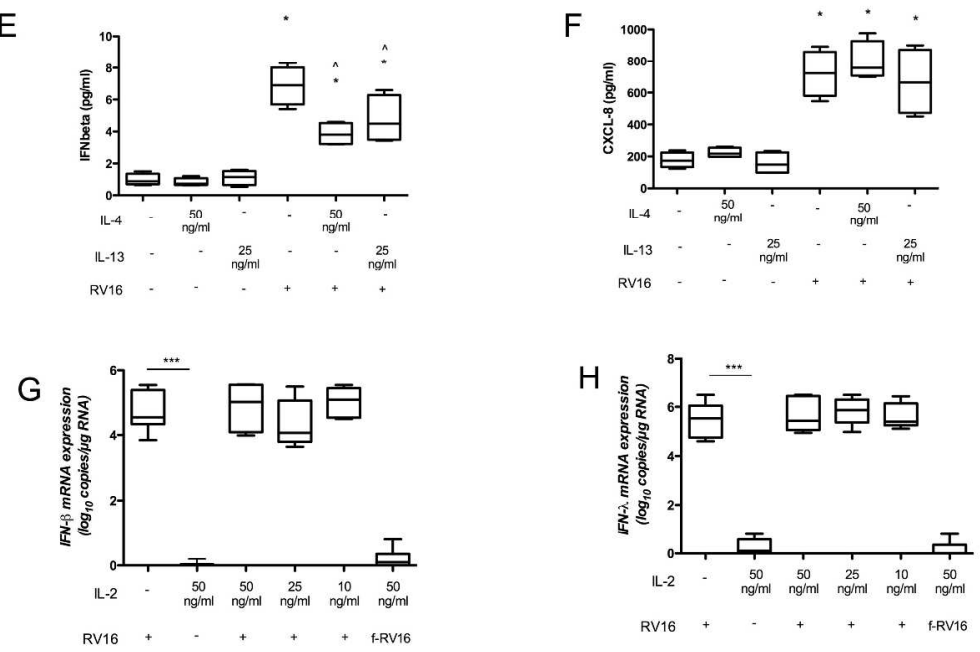

$241 \times 355 \mathrm{~mm}(300 \times 300$ DPI) 
Allergy

Page 60 of 63

Figure 2
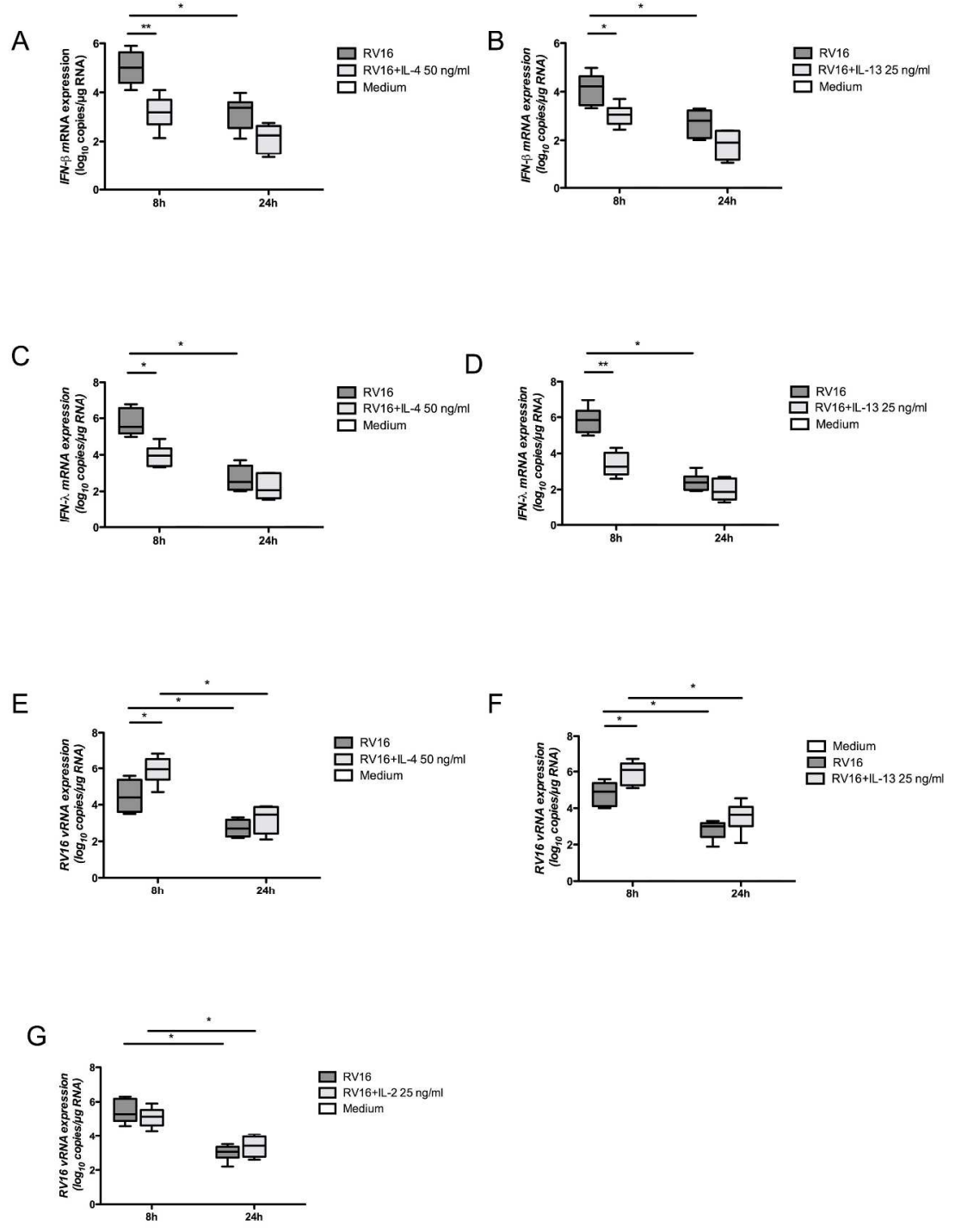

$247 \times 330 \mathrm{~mm}(300 \times 300$ DPI $)$ 


\section{Page 61 of 63}

1
2
3
4
5
6
7
8
9
10
11
12
13
14
15
16
17
18
19
20
21
22
23
24
25
26
27
28
29
30
31
32
33
34
35
36
37
38
39
40
41
42
43
44
45
46
47
48
49
50
51
52
53
54
55
56
57
58
60

Figure 3

A

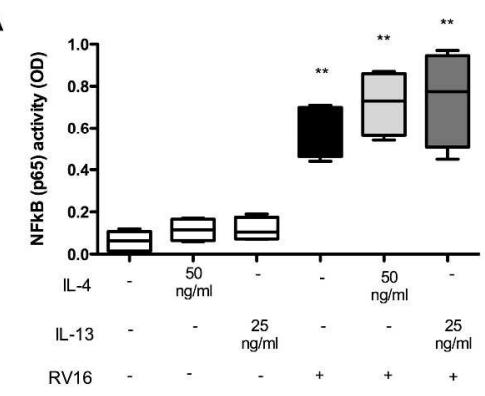

B

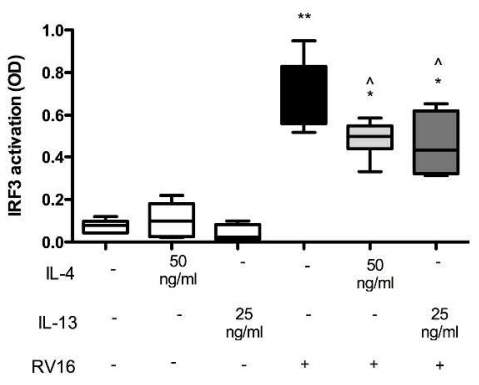

C

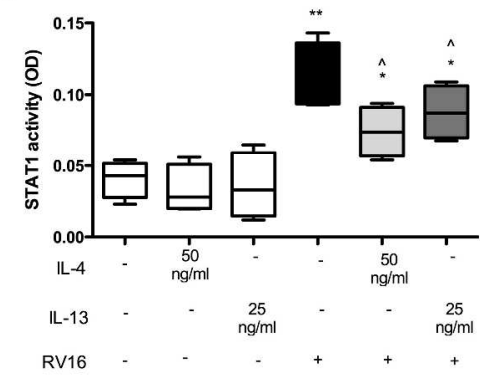

$253 \times 658 \mathrm{~mm}(300 \times 300$ DPI $)$ 
Figure 4
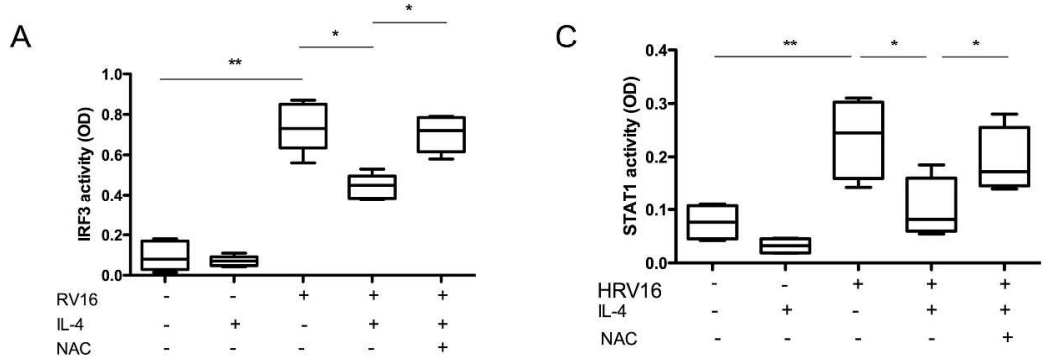

B

D
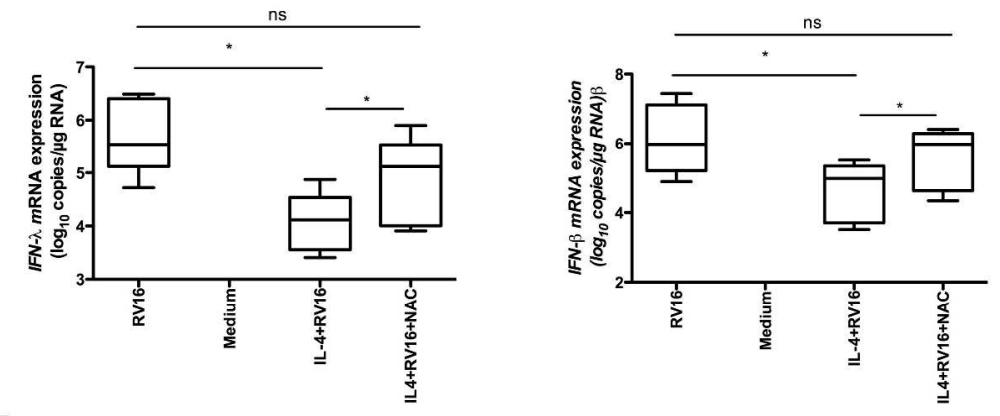

E

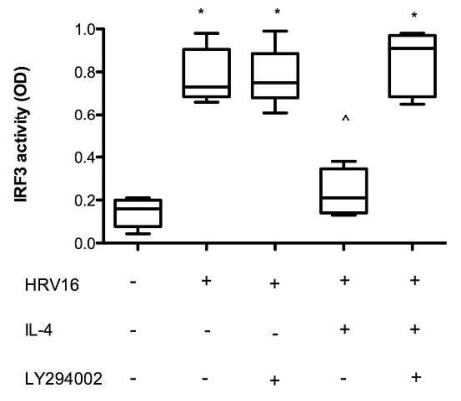

$244 \times 328 \mathrm{~mm}(300 \times 300$ DPI $)$ 


\section{Page 63 of 63}

Figure 5

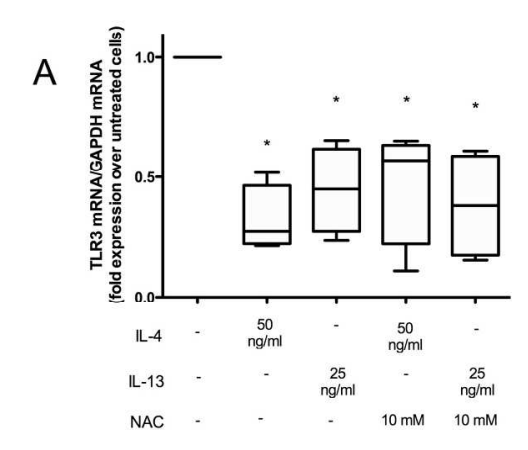

B

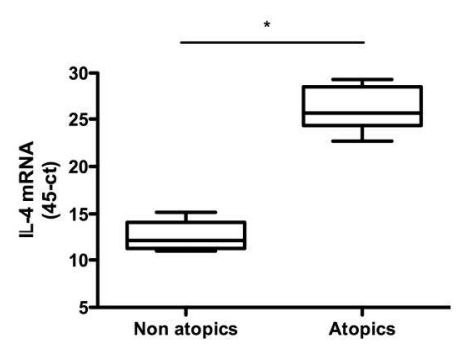

C

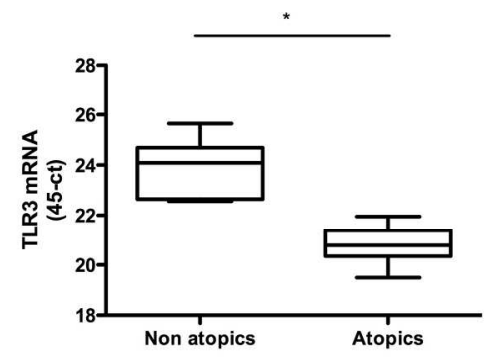

D

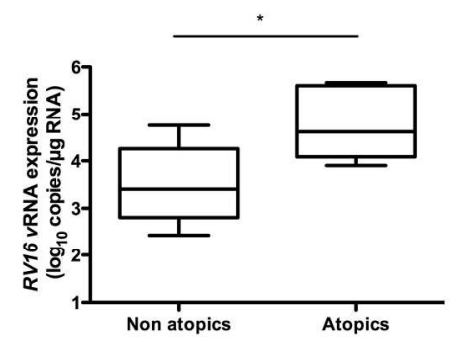

$203 \times 226 \mathrm{~mm}(300 \times 300 \mathrm{DPI})$

46

47

48

49

50

51

52

53

54

55

56

57

58

59

60 